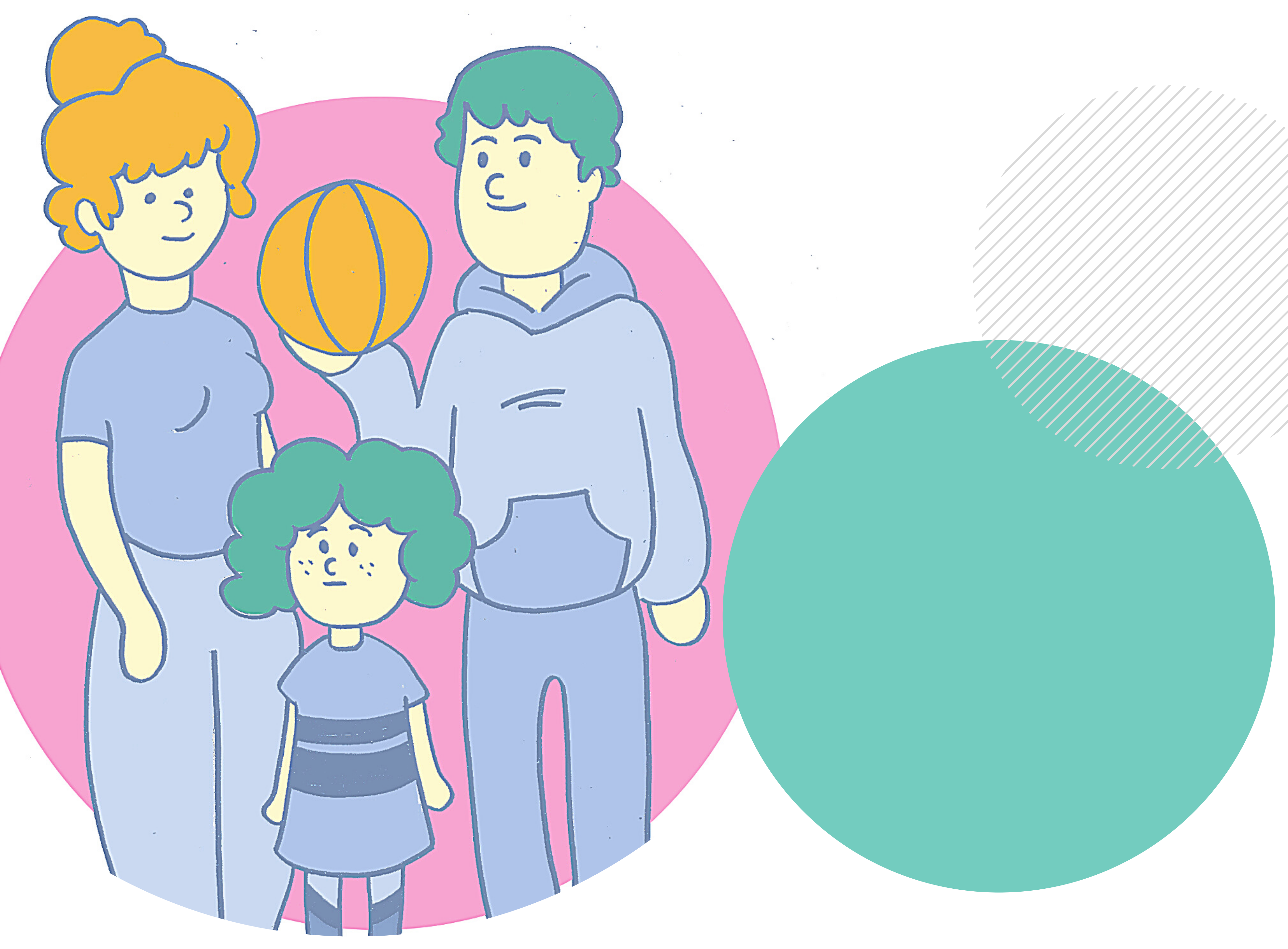

\title{
GUÍA PARA LA PROMOCIÓN DE ACTIVIDAD FÍ́SICA EN \\ PERSONAS CON TRASTORNO DEL ESPECTRO DEL AUTISMO
}

Laura Simón-Montañés

\begin{tabular}{|c|c|}
\hline 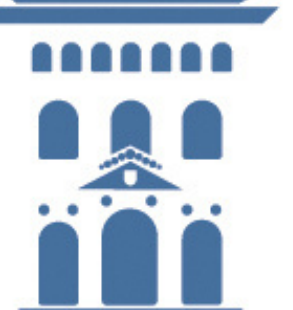 & $\begin{array}{l}\text { Servicio de } \\
\text { Publicaciones }\end{array}$ \\
\hline 151542 & Universidad Zaragoza \\
\hline
\end{tabular}





\section{Autoría y diseño}

\section{Laura Simón-Montañés}

\section{Colaboradores}

Asociación Autismo Huesca

Javier Sevil-Serrano

\section{Ilustraciones}

Maria de Luis Tello

\section{Editorial}

1. ${ }^{a}$ edición. Zaragoza, 2020

Servicio de Publicaciones. Universidad de Zaragoza

ISBN 978-84-16723-92-8 
4 | 


\section{Solbre esta guía}

Este documento va dirigido, especialmente, a los profesionales del ámbito educativo y deportivo. A través de esta guía, pueden conocer estrategias que se han mostrado efectivas para trabajar actividades físicodeportivas con personas con Trastorno del Espectro del Autismo (TEA). Del mismo modo, en este trabajo se presenta una experiencia educativa, deportiva y recreativa llevada a cabo con personas con TEA, socias de Asociación Autismo Huesca, familiares y profesionales de dicha entidad y alumnado de la Universidad de Zaragoza. Se trata también de un documento de especial interés para toda la comunidad educativa ya que ofrece pautas, recursos y materiales que facilitan la accesibilidad cognitiva en las personas con TEA. Por último, este trabajo pretende dar a conocer las características de estas personas e identificar las necesidades que presentan con la finalidad de involucrar a todos los agentes (familias y educadores, entre otros) en el diseño de actividades educativas y deportivas.

La elaboración de esta guía surge a través de una experiencia práctica desarrollada en una asignatura del Grado en Ciencias de la Actividad Física y del Deporte (CCAFD, Universidad de Zaragoza) en colaboración con Asociación Autismo Huesca. A partir de ahí, se ha creado una sinergia entre la autora de este trabajo y dicha asociación, cuyo objetivo principal es favorecer y promover la práctica de actividad física en las personas con TEA. Previo a la elaboración del presente trabajo, se colaboró en la iniciativa "TEA con A", con la publicación de una reseña en la página web de la asociación: "¿TE-Atreves a moverte?". En dicha iniciativa se puso la mirada en las mujeres con TEA dentro del contexto deportivo. Posteriormente, se presentó una experiencia educativa en el "Congreso internacional CAPAS-CITÉ. Liderazgo en la promoción de actividad física: estrategias efectivas en la movilización de activos", bajo el título: "Trastorno del Espectro Autista (TEA) y promoción de la actividad física: una experiencia inclusiva a través del desarrollo de habilidades motrices básicas". Estas acciones son el preludio al desarrollo de esta guía. 
61 


\section{Agradecimientos}

La elaboración de esta guía ha sido posible gracias a la colaboración de varias personas.

Gracias a Asociación Autismo Huesca y, especialmente, a María Pescador Vallés y Diego López Pueyo por la implicación y las aportaciones.

A Javier Sevil Serrano, maestro y profesor de Educación Física y Doctor en Educación, por la participación y la revisión exhaustiva de este documento.

A María de Luis Tello por la realización de ilustraciones para facilitar la comprensión de algunas ideas y dinamizar la lectura de este trabajo.

Asimismo, agradecer a los socios/as y familias de Asociación Autismo Huesca y estudiantes de la Universidad de Zaragoza la participación en la experiencia práctica. Del mismo modo, a los compañeros y al profesorado de las asignaturas "Actividad física y poblaciones especificas" y "Actividad física y deporte adaptado a las personas con discapacidad" del Grado en CCAFD por los aprendizajes obtenidos durante las clases teórico-prácticas y seminarios. 


\section{TABLA DE CONTENIDO}

1.Trastorno del Espectro del Autismo, ¿has oído hablar de ello?

1.1.Definición de Trastorno del Espectro del Autismo

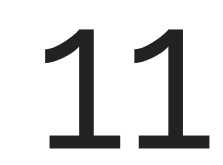

1.2. Características asociadas al Trastorno del Espectro del Autismo

15

2.La comunicación en el Trastorno del Espectro del Autismo

2.1. Sistemas Alternativos y / o Aumentativos de Comunicación

2.2. Apoyo visual

5. Estrategias para el diseño de actividades físico-deportivas en personas con Trastorno del Espectro del Autismo 
101 


\section{Trastorno del del Espectro del Autismo, ¿has oído hablar de ello?}

\subsection{Definición de Trastorno del Espectro del Autismo}

A pesar de que el término "autismo" fue definido por primera vez en la década de 1940, su origen y parte de su naturaleza continúa siendo objeto de estudio (Hodges, Fealko y Soares, 2020). En la actualidad, se estima que uno de cada 59 niños tiene algún rasgo de Trastorno del Espectro del Autismo (TEA), siendo una cifra muy superior respecto a años anteriores (Baio et al., 2018). Por ello, los educadores físicos podrian tener contacto con alumnado con TEA en algún momento de su trayectoria profesional. Sin embargo, estudios previos han revelado, en los docentes de Educación Física (EF) (Beamer y Yun, 2014) y en los educadores físicos (Duquette, Carbonneau, Roult y Crevier, 2016), una insuficiencia de conocimientos para promover la actividad física (AF) en personas con rasgos de TEA. En base a ello, parece necesario conocer, en primer lugar, la definición y las características que se asocian a este trastorno $y$, en segundo lugar, estrategias metodológicas efectivas para diseñar e implementar actividades físico-deportivas para estas personas.

El término TEA hace referencia a la alteración de algunas de las funciones que se desarrollan en los primeros años de vida (Asún, 2016). Además, engloba diferentes trastornos que, siendo diferentes, presentan características parecidas. Es por ello que se hace referencia a "trastorno del espectro", para englobar una gran variedad de trastornos con características similares en: 1) la reprocidad social, 2) la comunicación y 3) las conductas restrictivas y repetitivas (American Psychiatric Association, 2014; Riviere, 2001). En este sentido, el Manual Diagnóstico y Estadístico de Trastornos Mentales (DSM-5; American Psychiatric Association, 2014) especifica que tanto el trastorno autista, el sindrome de Asperger y el trastorno generalizado del desarrollo no especificado serán recogidos como TEA.
Las personas con TEA suelen presentar un desarrollo normal durante los primeros meses de vida. Posteriormente, pueden detectarse alteraciones en el lenguaje adquirido o en la interacción social (por ejemplo, no responder ante un estímulo auditivo). Del mismo modo, puede percibirse en estas personas un aislamiento social, dificultad para establecer contacto a través de la mirada $\mathrm{y} / \mathrm{o}$ cierta sobre-estimulación ante los cambios del entorno (por ejemplo, el cambio de un recorrido que hace todos los días, el cambio de la ubicación de un mueble, un nuevo sabor en una comida, etc.). En relación al juego, comienzan a realizar actividades rutinarias y repetitivas, normalmente interactuando con objetos. Asimismo, los niños/as con TEA podrían mostrar un enorme interés por determinados objetos o actividades o sentir gran fascinación por determinados elementos (por ejemplo, un tejido o el color de un cuaderno). Por ello, la privación de estas experiencias les podría ocasionar enfado o malestar (Rivière, 2001; Wing y Potter, 1999).

EL TEA engloba diferentes

trastornos que, siendo

diferentes, presentan

características parecidas.

\subsection{Características asociadas al Trastorno del Espectro del Autismo}

Las manifestaciones del TEA pueden ser muy diversas, no existiendo dos personas con la misma afectación (Fittipaldi-Wert y Mowling, 2009). A continuación, se especifican las características que se asocian a este trastorno, recogidas en el DSM-5 (American Psychiatric Association, 2014): 
Deficiencias persistentes en la comunicación e interacción social:

\section{- Deficiencias en la reciprocidad socioemocional:} varían desde un acercamiento social anormal y un fracaso en la conversación bidireccional, con una disminución en los intereses o en la manifestación de emociones, hasta el fracaso total para iniciar o responder a las interacciones sociales.

- Deficiencias en las conductas comunicativas no verbales: pueden oscilar desde una comunicación verbal y no verbal, con escaso contacto visual, anomalías en el lenguaje corporal o dificultad en la comprensión y el uso de gestos, hasta una ausencia de expresión facial y comunicación no verbal.

- Deficiencias en el desarrollo, mantenimiento y comprensión de las relaciones: pudiendo encontrar dificultades para regular y ajustar el comportamiento a los diferentes contextos sociales, jugar a juegos imaginativos y hacer amigos o empatizar con los intereses de otras personas.

Patrones restrictivos y repetitivos de comportamiento:

- Movimientos, utilización de objetos o habla estereotipada o repetitiva: hace referencia a la ecolalia (es decir, repetición de una palabra o frase que ha pronunciado otra persona), las frases idiosincrásicas o que no son comunicativas (por ejemplo, utilizar un lenguaje adecuado pero ligado a un interés Icomo, por ejemplo, llamar a las personas por la edad]), la alineación o el cambio de lugar de los objetos o juguetes y los movimientos esterotipados (movimientos repetitivos que normalmente suelen coincidir con momentos que les generan ansiedad, como un balanceo, un aleteo con las manos o dar golpes; Wing y Potter, 1999).
- Insistencia en la monotonía, excesiva inflexibilidad de rutinas o patrones ritualizados de comportamiento verbal o no verbal: por ejemplo, estas personas podrian sentir angustia ante un pequeño cambio, desarrollar patrones de pensamientos rígidos, tener la necesidad de tomar siempre el mismo camino, etc.

- Intereses restringidos y fijos que suelen ser anormales en cuanto a su intensidad: por ejemplo, sentir un fuerte apego o preocupación por un material u objeto específico (un peluche, unas llaves, etc.), así como presentar intereses muy perseverantes.

- Hiperactividad o hipoactividad a los estímulos sensoriales 0 interés inhabitual por aspectos sensoriales del entorno: por ejemplo, indiferencia al dolor 0 a la temperatura, respuesta adversa a algunos sonidos, olfateo 0 palpación excesiva de los objetos o incluso fascinación por las luces o el movimiento. Estos comportamientos podrian explicarse por la falta de comprensión del entorno que les rodea, así como por la dificultad para interactuar con él. Por lo tanto, supondría una manera de canalizar la frustración o el estrés.

En relación al grado de afectación, la American Psychiatric Association (2014) determina tres niveles en función de las deficiencias que presentan las personas con TEA en la comunicación y en los comportamientos repetitivos y restrictivos: Grado 1 "necesita ayuda", Grado 2 "necesita ayuda notable" y Grado 3 "necesita ayuda muy notable" (Figura 1):

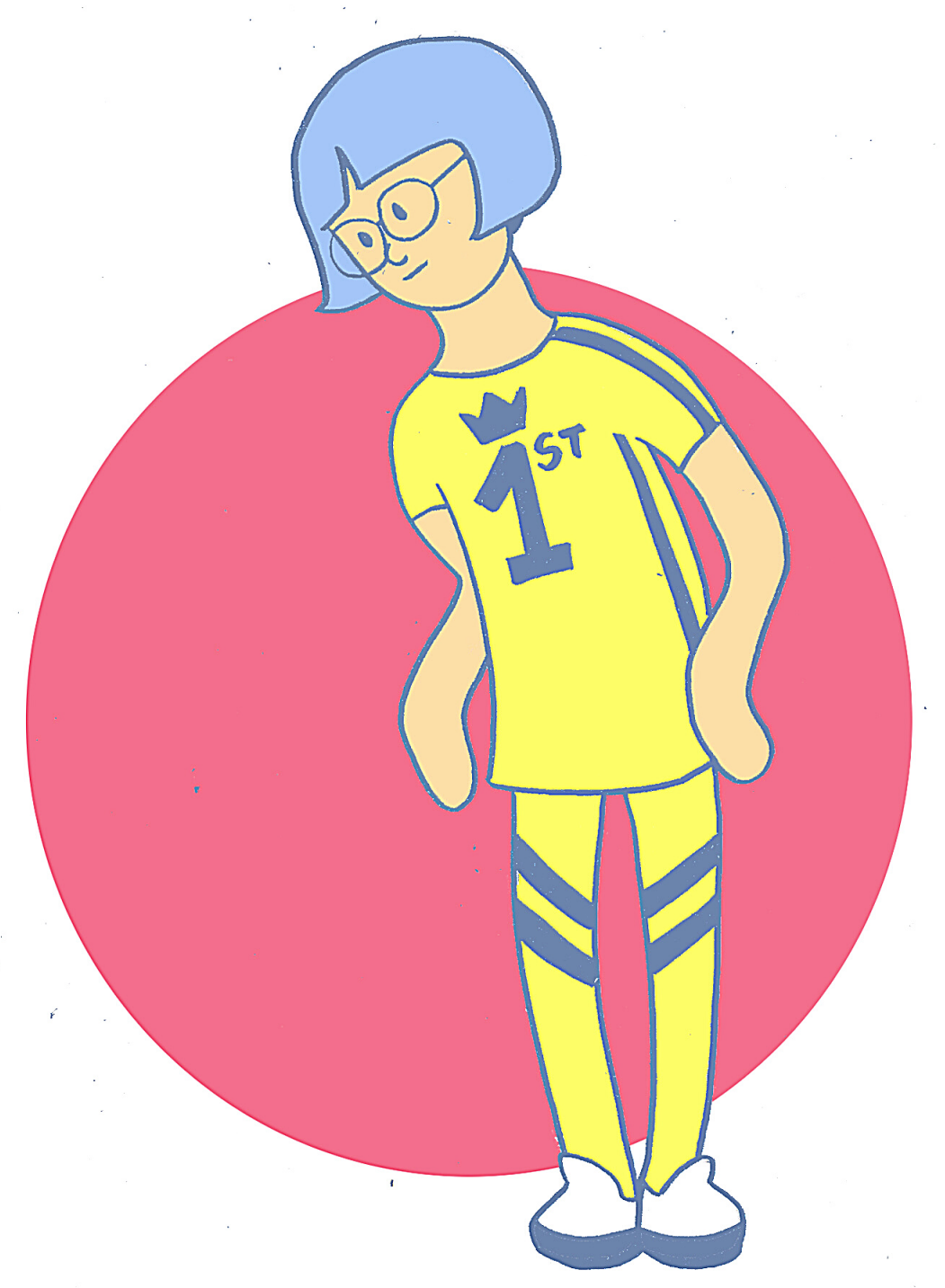




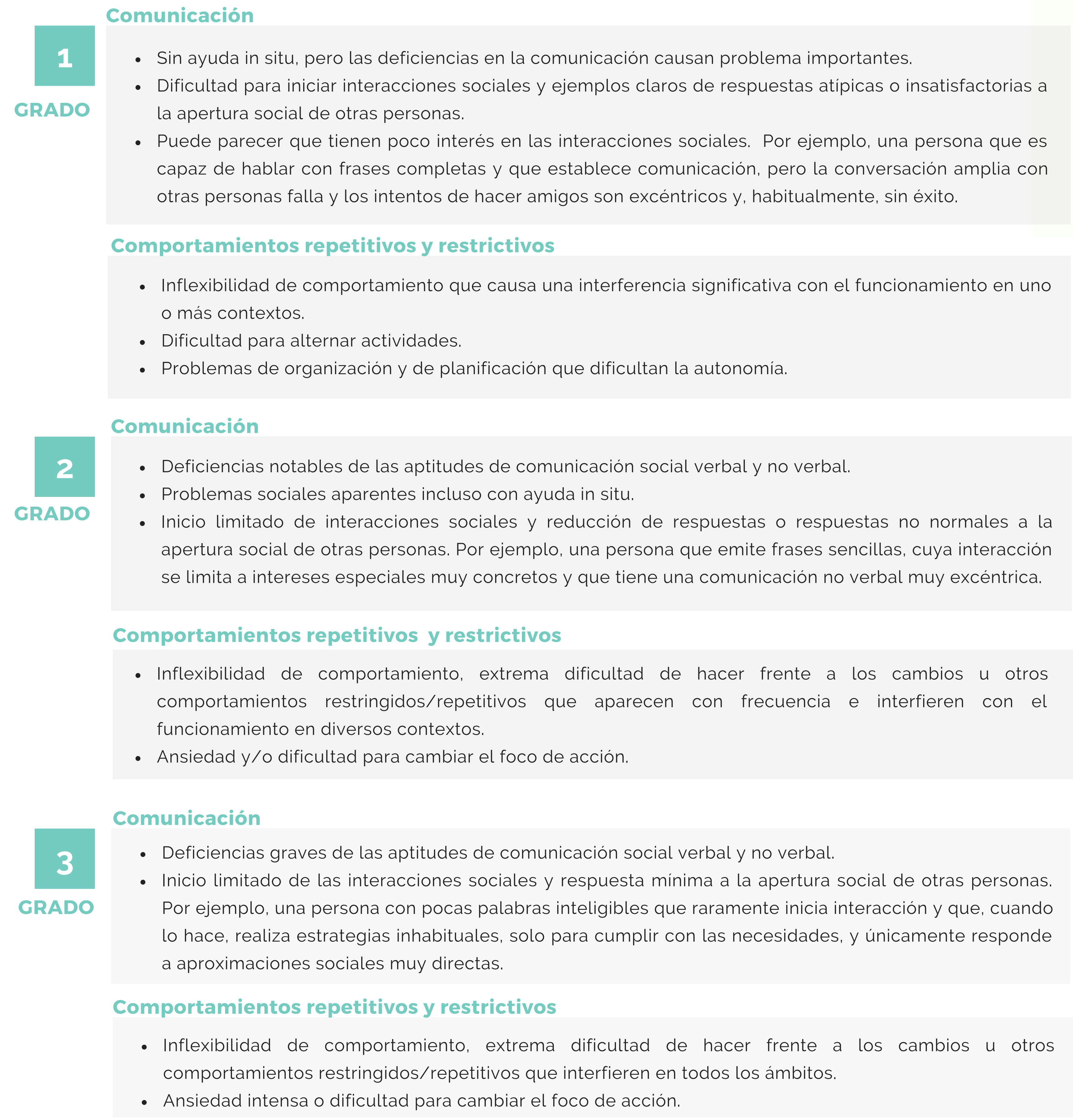

\section{Las siglas DSM hacen referencia a \\ "Manual Diagnóstico y Estadístico de los Trastornos Mentales"}

("Diagnostic and Statistic Manual of Mental Disorders"). 
Siguiendo el DSM-5, el TEA puede aparecer con o sin déficit intelectual acompañante, con o sin deterioro del lenguaje acompañante, asociado a una afección médica o genética (por ejemplo, el TEA asociado al sindrome de RETT luna enfermedad genética]) o asociado a otro trastorno del desarrollo neurológico, mental $\mathrm{O}$ del comportamiento (American Psychiatric Association, 2014).

A nivel neuromotor, las personas con TEA podrían poseer un gran desarrollo de la motricidad fina $y$, por el contrario, un menor desarrollo de la motricidad gruesa. Sin embargo, algunas personas poseen un déficit en ambos tipos de motricidad (Asún, 2016; Bhat, Landa y Galloway, 2011; Stins y Emck, 2018). Diversas investigaciones han demostrado que los niños con TEA desarrollan habilidades motoras de forma diferente, a veces presentando un mayor retraso, en comparación con sus homólogos neurotípicos (personas sin rasgos TEA) (Colombo-Dougovito y Block, 2019; Downey y Rapport, 2012). Otros estudios revelan una limitación en habilidades como la coordinación motora, el control postural o el equilibrio (Bhat et al., 2011; Stins y Emck, 2018). No obstante, parecen necesarias más investigaciones que sigan determinando otras de las caracteristicas de estas personas a nivel motor (Bhat et al., 2011).

Las características asociadas al TEA no se corresponden únicamente con dificultades. La Confederación Autismo España enuncia una serie de capacidades asociadas a este trastorno (Confederación Autismo España):

\section{Es imprescindible potenciar las capacidades de estas \\ personas, así como minimizar sus dificultades.}

- Buena respuesta y seguimiento de las rutinas.

- Competencias en tareas repetitivas y mecánicas.

- Sinceridad.

- Honestidad.

- Meticulosidad.

- Curiosidad por determinados temas.

- Conocimiento especializado en los temas que les suscitan interés.

- Cumplimiento y respeto de las reglas.

- Atención a los detalles.

- Tendencia a ser personas muy lógicas.

- Capacidad de escucha, sin prejuicios.
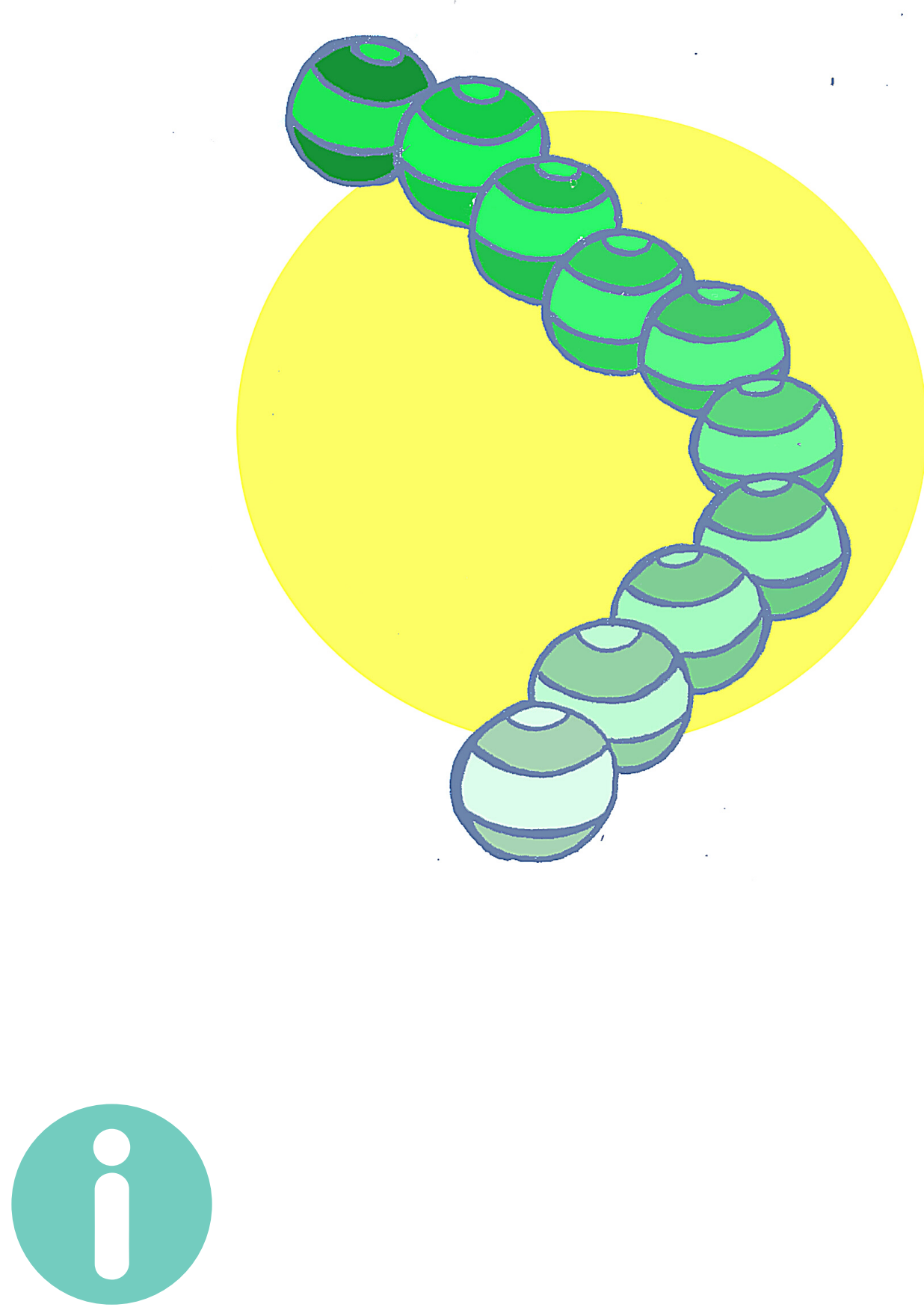

Para más información sobre las
características del TEA, consultar la
página de Confederación Autismo España:

http://www.autismo.org.es/sobre-los-TEA 


\section{La comunicación en el Trastorno del Espectro del Autismo}

Existe una gran diversidad en los canales de emisión y recepción de información en las personas con TEA. Algunas personas poseen habilidades lingüísticas adecuadas, sin embargo, tienen dificultad para establecer una comunicación bidireccional o reciproca. Otras personas no utilizan el lenguaje verbal y requieren apoyos que sustituyen al lenguaje oral. Por otro lado, existen personas con ausencia de comunicación verbal y con dificultad para comprender los gestos o las expresiones de la comunicación no verbal (como, por ejemplo, la expresión facial o la postura corporal, entre otros) (Confederación Autismo España).

\subsection{Sistemas Alternativos y/o Aumentativos de Comunicación}

Para favorecer los procesos comunicativos en las personas con TEA existen apoyos que sustituyen o complementan al lenguaje oral. Estos sistemas son conocidos como Sistemas Alternativos $\mathrm{y} / \mathrm{o}$ Aumentativos de Comunicación (SAAC). El Portal Aragonés de la Comunicación Aumentativa y Alternativa (ARASAAC) define los SAAC como "formas de expresión distintas al lenguaje hablado que tienen como objetivo aumentar (aumentativos) y/o compensar (alternativos) las dificultades de comunicación y lenguaje de muchas personas con discapacidad". A través de ellos, las personas con TEA podrian interaccionar y comunicarse con el medio (Cudolá, 2016).

Existen diversos sistemas de clasificación de los SAAC (por ejemplo, modalidad gestual, visual o escrita). A continuación, se describen algunos de ellos:

\section{Modalidad gestual:}

Uno de los más conocidos es el Sistema de Benson Schaeffer. Este programa incluye dos elementos: 1) el componente es el habla signada y 2) la comunicación es simultánea (Barrios, Blau y Forment, 2018). Por lo tanto, supone realizar de forma simultánea la comunicación oral y gestual. De esta forma, si la persona tiene dificultades en la comunicación oral podría procesar la información a través de los signos (Gómez, Valero, Peñalber y Velasco, 2008).

Este método podría ser adecuado para las personas con diversidad funcional intelectual o trastornos del lenguaje. La finalidad principal de este programa es promover el desarrollo de signos de una forma espontánea, posteriormente el desarrollo del habla signada y, por último, el lenguaje verbal espontáneo (Barrios, et al. 2018).

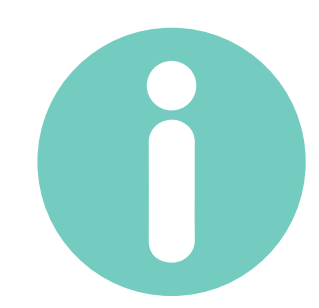

La web "Habla signada" permite la traducción de una palabra a animaciones, vídeos, pictogramas, imágenes o sonidos.

https://hablasignada.divertic.org/buscar.php

Para más información se puede visualizar la página del Gobierno de Aragón ARASAAC:

http://www.arasaac.org/ 


\section{Modalidad visual:}

Un ejemplo de esta modalidad es el Sistema de Comunicación por Intercambio de Figuras (PECS). Este programa supone la comunicación a través del intercambio de imágenes entre una persona no hablante y el interlocutor. A través de estos elementos, se puede emitir una información, responder, etc.

Este método podría ser adecuado para las personas que tienen dificultad en la adquisición del lenguaje o que presentan un déficit significativo para comunicarse (Barrios et. al., 2018). La finalidad de este recurso consiste en promover el aprendizaje para comunicarse en un contexto social (Barrios et al., 2018).

Para poder llevar a cabo este intercambio de imágenes son necesarios otros materiales como velcros, plastificadoras, páginas para insertar las figuras, etc. Algunos estudios que han trabajado este sistema en las clases de EF han demostrado su efectividad, sin embargo, su implementación puede requerir la formación de los docentes y la colaboración con un equipo multidisciplinar (Green y Standt, 2013)

\subsection{Apoyo visual}

LoS SAAC no deben de confundirse con otro tipo de apoyos visuales como los esquemas, el lenguaje escrito, las agendas visuales, los dibujos, los Sistemas Pictográficos de Comunicación (SPC), el objeto real o las fotografías, entre otros. Una de las diferencias entre los SAAC y los apoyos visuales es que en los primeros se introducen más canales de comunicación como el lenguaje oral, el gestual o el escrito. En el contexto educativo, los apoyos visuales se utilizan para proporcionar información al estudiante con TEA (sobre un espacio, un comportamiento adecuado o lo que se espera de ellos) (Barrios et al., 2018). Del mismo modo, estos recursos proporcionan predictibilidad y anticipación $y$, en consecuencia, contribuyen a reducir la ansiedad al preparar al alumnado para la actividad (Fittipaldi-Wert y Mowling, 2009; Menear y Neumeier, 2015).
Sin embargo, dado que no todas las personas interpretan de la misma forma una imagen, estos apoyos deben de adaptarse al grupo-clase. Por ejemplo, con unas personas puede ser adecuado trabajar con fotografias, con otras mediante el objeto real, con otras a través de un dibujo elaborado por el docente, etc. El recurso que se utilice debe ser significativo para que la persona lo pueda procesar, lo que dependerá de su nivel de representación y de su capacidad cognitiva.

Por lo tanto, los apoyos visuales permiten la "accesibilidad cognitiva" hacia el entorno y hacia la actividad ya que no saber qué hacer o cuándo hacerlo podría generar confusión o ansiedad en estas personas (Fittipaldi-Wert y Mowling, 2009).

Otros recursos que

favorecen la comunicación son los productos de

apoyo: comunicadores de habla artificial, ordenadores personales o tabletas. Estos dispositivos electrónicos pueden incorporar sistemas ortográficos, pictográficos o salidas de voz (ARASAAC).

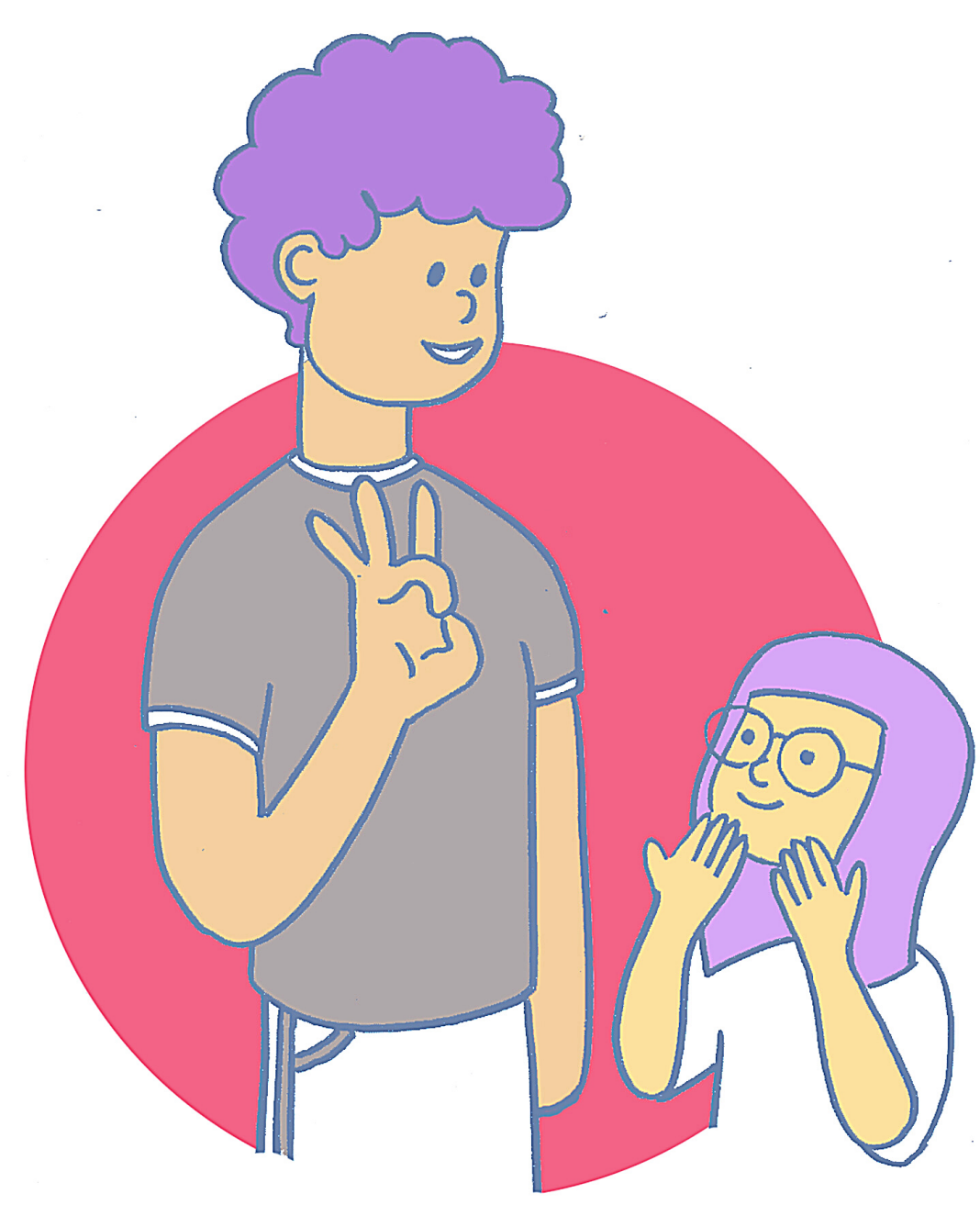




\title{
¿Por qué es importante promover la actividad física en personas con Trastorno del Espectro del Autismo?
}

\author{
Recomendaciones de actividad física, ¿las conoces? (Figura 2)
}

Recomendaciones de actividad física para niños/as y jóvenes de 5 a 17 años

1

- Se debe realizar un mínimo de 60 minutos diarios de AF de intensidad moderada a vigorosa.

- Realizar más de 60 minutos de AF diarios a esta intensidad reportará mayores beneficios para la salud.

- La AF debería ser, en su mayor parte, aeróbica. Además, parece oportuno incorporar, al menos, tres días a la semana actividades vigorosas de fortalecimiento muscular.

\section{Recomendaciones de actividad física para adultos de 18 a 64 años}

- Se debe realizar 150 minutos de AF aeróbica de intensidad moderada o 75 minutos de AF aeróbica vigorosa cada semana o una combinación equivalente de ambas. Las sesiones de esta AF serán de 10 minutos de duración, como mínimo.

- Realizar hasta 300 minutos de AF moderada o 150 minutos de AF vigorosa a la semana o una combinación equivalente de ambas reportará mayores beneficios en la salud.

- Además, parece oportuno realizar actividades de fortalecimientos de los grandes grupos musculares, al menos, dos o más veces por semana

¿Son las mismas recomendaciones para las personas con diversidad funcional?

- Se recomienda comenzar poco a poco a practicar AF, aumentando de forma progresiva la duración, la frecuencia y la intensidad.

- En los jóvenes que tienen dificultades para cumplir las recomendaciones de AF, se recomienda adoptar un estilo de vida activo. Realizar algún tipo de AF es mejor que no hacer nada.

- Los jóvenes con diversidad funcional pueden consultar al profesional de la salud, u otros profesionales del área de la AF y del deporte adaptado, el tipo y cantidad de AF recomendada para ellos.

Figura 2. Recomendaciones de AF (Organización Mundial de la Salud 2010; 2020)

Dado los innumerables beneficios que reporta la práctica de AF, existe la necesidad de desarrollar actividades físico-deportivas para todas las personas y niveles de funcionamiento (Sorensen y Zarrett, 2014). La falta de actividades deportivas programadas en niños/as, adolescentes y jóvenes adultos con diversidad funcional conlleva una ocupación del tiempo libre con actividades sedentarias $y$, en consecuencia, presentan menores niveles de AF respecto a sus iguales sin diversidad funcional (LaLonde, MacNeill, Eversole, Ragotzy y Poling, 2014; Liang, Li, Wong, Sum y Sit, 2020; Lobe-
nius-Palmér, Sjöqvist, Hurtig-Wennlöf y Lundqvist, 2018). Del mismo modo, una investigación reveló mayores niveles de obesidad en adolescentes con TEA respecto a sus homólogos neurotípicos (23.3\% vs $12,5 \%$; McCoy y Morgan, 2020). Por lo tanto, la AF podría ser una forma de prevenir y/o revertir el sobrepeso y la obesidad (Weihrauch-Blüher, Schwarz y Klusmann, 2018) y, además, minimizar la aparición de enfermedades no transmisibles derivadas de un alto tiempo dedicado a actividades sedentarias (Dempsey et al., 2020; Patterson et al, 2018). 


\section{El término "nivel de}

\section{funcionamiento" hace}

referencia al perfil de

neurodesarrollo global de

la persona, la

sintomatología TEA, La

capacidad intelectual, el

lenguaje, el nivel de

autonomía y las posibles

comorbilidades, entre otras.

Por ello, deben incrementarse las oportunidades de práctica de AF en las personas con diversidad funcional, especialmente, en las personas con TEA (McCoy y Morgan, 2020). Recientes estudios han demostrado que la práctica regular de AF es eficaz para mejorar las deficiencias en las áreas afectadas en niños/as con TEA (Aniszewski, Almeida y Alvernaz, 2020). Algunas revisiones sistemáticas y meta-análisis han determinado una mejoría en niños/as y adolescentes en el trastorno de la reciprocidad social y de la comunicación verbal, así como en el área social (Howells et al., 2019; Huang, Du, Liu y Tan, 2020; Reinders, Branco, Wright, Fletcher y Bryden, 2019). Esta área es de especial importancia ya que tiene una relación bidireccional con la práctica de AF. Así, las características en el área social de la persona parecen influir en la práctica de AF y, a su vez, realizar AF puede mejorar las relaciones interpersonales (Reinders et al., 2019). Por otro lado, aunque algunas investigaciones han revelado que la práctica de AF mejora las habilidades motrices básicas en niños/as y adolescentes (Colombo-Dougovito y Block, 2019; Huang et al., 2020; Ruggeri, Dancel, Johnson y Sargent, 2019), parecen necesarios más estudios que examinen los efectos de la práctica de AF en el aprendizaje motor en estas personas (Ruggeri et al., 2019). En este sentido, una mejora en el comportamiento motor también podría incrementar la práctica de AF (al percibirse más competentes) y, en consecuencia, favorecer las habilidades sociales (Colombo-Dougovito y Block, 2019).
Los entornos de práctica de AF también han demostrado minimizar los comportamientos inapropiados en estudiantes con TEA (comportamientos como gritar, morder o golpear, entre otros) (Sherman, 2019). Sin embargo, los efectos de la AF en la disminución de los comportamientos estereotipados en niños/as, adolescentes y adultos han demostrado ser efectivos en algunas investigaciones (Lang et al., 2010; Suárez-Manzano, López-Serrano, de Oliveira y da Cruz Murta, 2019) y, en otras, los cambios fueron escasos (Huang et al., 2020). Del mismo modo, recientes estudios han revelado una asociación positiva entre la AF y algunas funciones cognitivas y rendimiento académico en niños/as, adolescentes y jóvenes adultos con TEA (Fedewa y Ahn, 2011; Nakutin y Gutiérrez, 2019; Tan, Pooley y Speelman, 2016) (Figura 3).

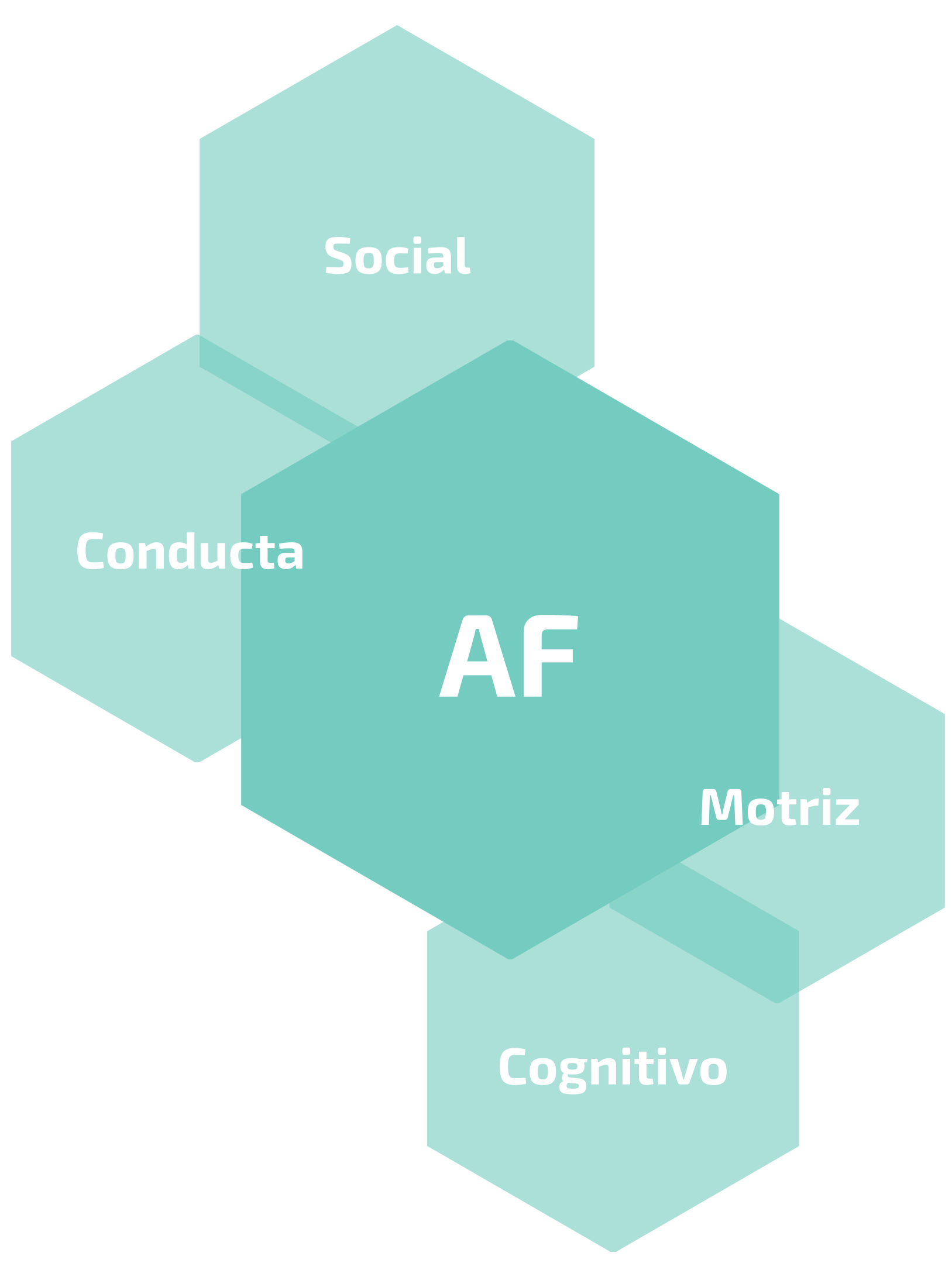

Figura 3. Beneficios de la AF en personas con TEA 
Por lo tanto, la práctica regular de AF y la reducción del tiempo sedentario podría producir efectos positivos en la salud física, conductual y social de las personas con TEA (Huang et al., 2020; Jones et al., 2017), mejorando su calidad de vida (Cuesta et al., 2017; Reinders et al., 2019). Por ello, algunos autores han señalado la necesidad de promover la práctica regular de AF en estas personas (Liang et al., 2020) con la finalidad de obtener todos los beneficios que se asocian a este comportamiento.

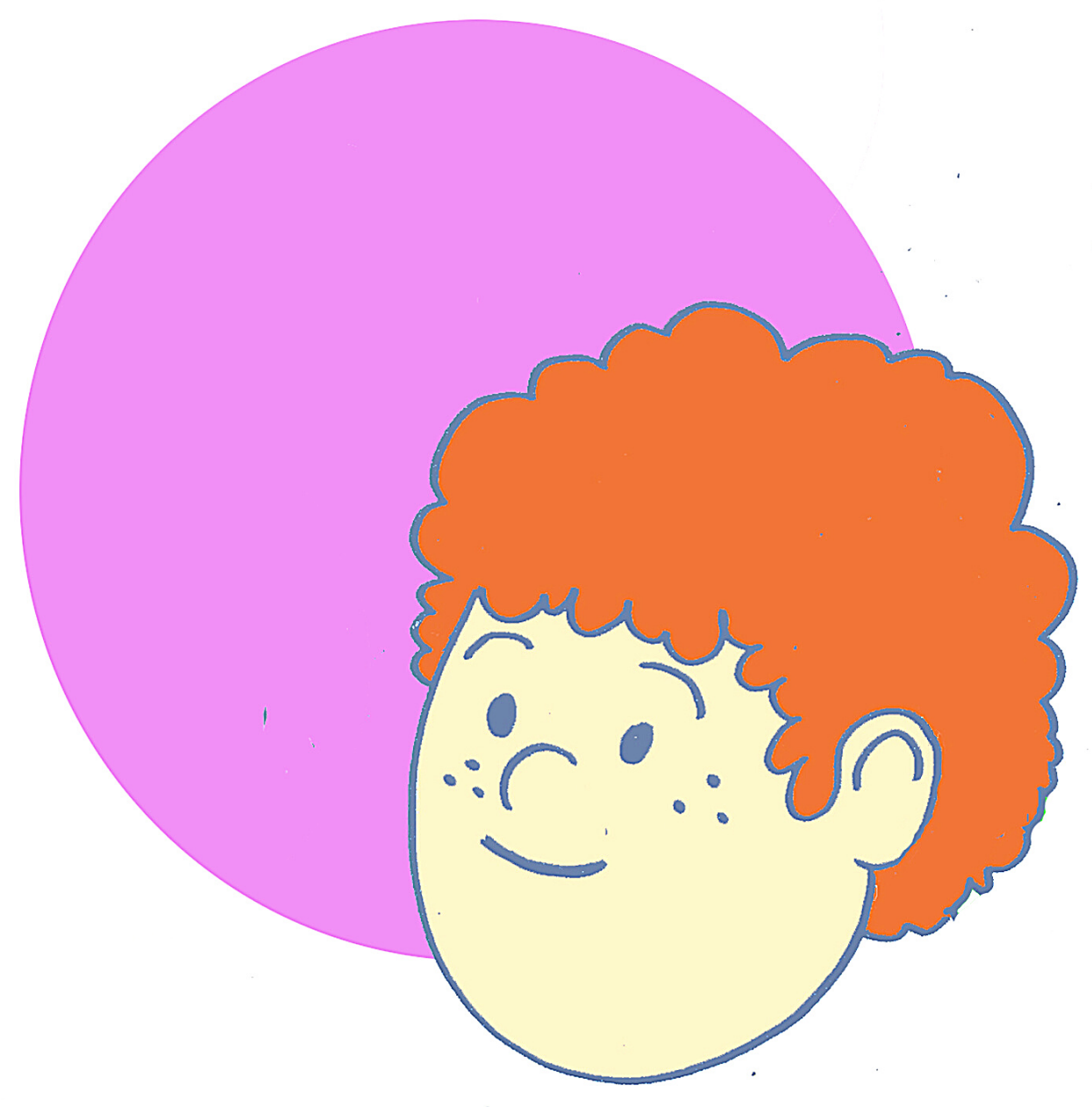

\section{Recomendaciones de $\mathbf{2 4}$ horas de movimiento en niños/as y adolescentes}

Tanto el tiempo que pasamos en movimiento como el que permanecemos sin movernos inciden en nuestra salud (Chaput, Carson, Gray y Tremblay, 2014). No solo es importante cumplir las recomendaciones de AF (al menos 60 minutos/día de AF a una intensidad moderada o vigorosa) sino que también es imprescindible cumplir las recomendaciones de duración de sueño (9-11 horas en niños y 8-10 horas en adolescentes) y de tiempo sedentario (limitar el tiempo sedentario y reducir a menos de 2 horas/día el tiempo de pantallas) (Tremblay et al., 2016) (Figura 4).

Estos tres comportamientos (AF, sueño y tiempo sedentario) interaccionan durante las 24 horas que tiene el día (Chaput et al., 2014; Tremblay et al., 2016). La importancia de este enfoque radica en que el tiempo que le dedicamos a un comportamiento se lo restamos a otro (por ejemplo, cuanto más tiempo estemos sentados a lo largo del día, menos tiempo podremos destinar a hacer AF o dormir). Por ello, se recomienda limitar el tiempo que permanecemos sentados y aumentar la AF ligera durante varias horas al día (por ejemplo, caminar).

\section{Recomendaciones de 24 horas de movimiento en niños/as con TEA}

Según el estudio desarrollado por Healy et al. (2020), los niños/as que cumplen las recomendaciones de AF (igual o superior a 1 hora), sueño (9-11 horas) y tiempo de pantalla (inferior a 2 horas/dia) tienen menor probabilidad de desarrollar obesidad respecto a los que no las cumplen. Asimismo, esta investigación demostró que los niños/as neurotípicos cumplian más las recomendaciones de 24 horas de movimiento en comparación con los niños con TEA. Concretamente, un $58.3 \%$ y un $41.7 \%$ de los niños/as con TEA cumplián las recomendaciones de tiempo de pantalla y actividad física respectivamente, frente a un $80.6 \%$ y un $69.4 \%$ en niños/as neurotípicos. Por otro lado, el $44.4 \%$ de los niños/as con TEA cumplian dos de estas tres recomendaciones, mientras que un $55.6 \%$ de los niños/as neurotípicos cumplian las tres recomendaciones. Dado que otros estudios han señalado que el conocimiento de las recomendaciones de estos comportamientos favorece su cumplimiento (LeBlanc et al., 2016), parece necesario promover su difusión en los niños/as y jóvenes con TEA.

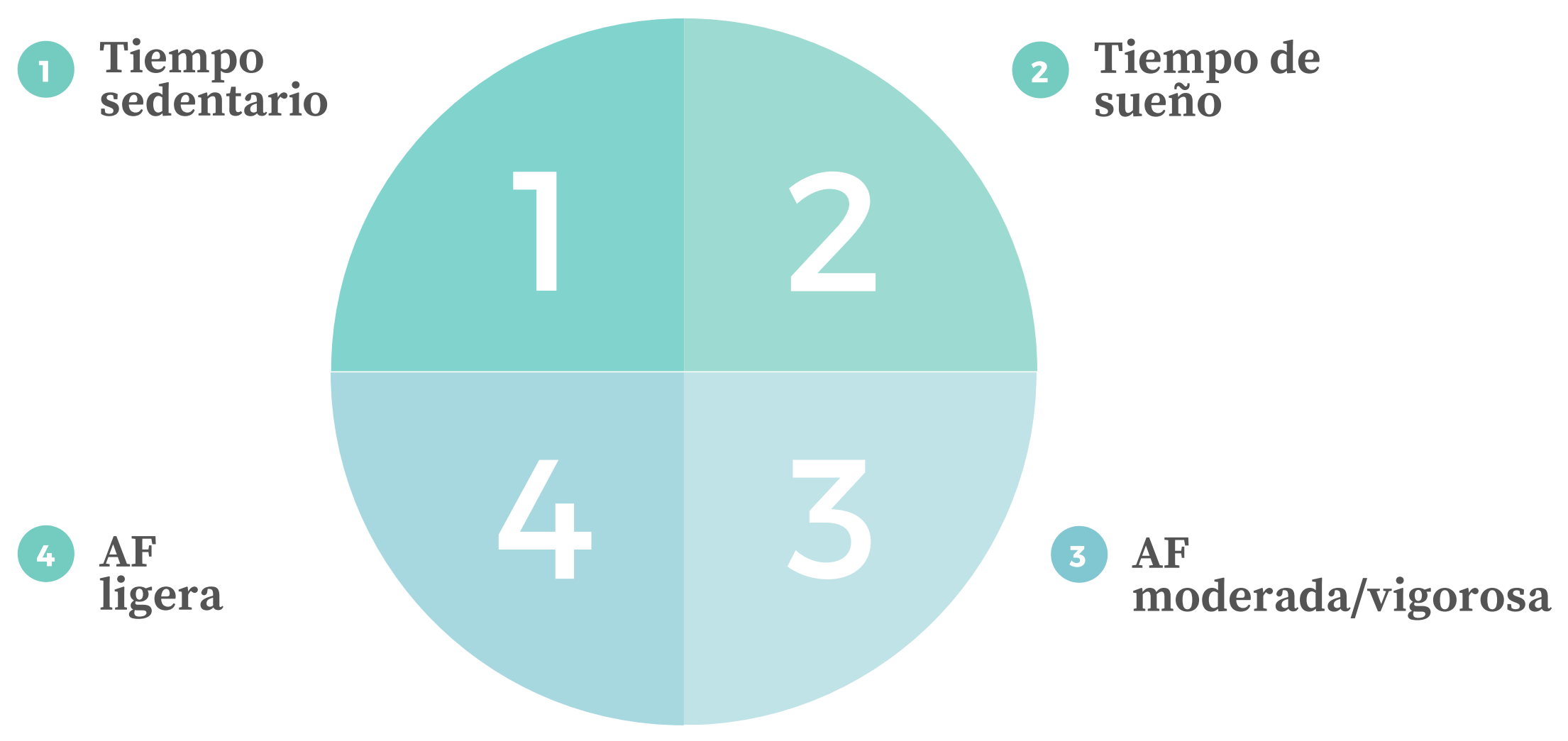

Figura 4. Comportamientos que representan las 24 horas del día (Chaput et al., 2014; Tremblay et al., 2016) 


\section{Barreras para la práctica de actividad física en personas con Trastorno del Espectro del Autismo}

Las personas con TEA tienen menos posibilidades de participar en programas de AF que sus homólogos neurotípicos (Duquette et al., 2016). Recientes investigaciones han analizado las principales barreras para la práctica de AF que perciben las personas con TEA. Por ejemplo, en el estudio de Varin (2019) se identificaron tres barreras principalmente (Figura 5):

\section{Individuales. \\ 2. Familiares \\ 3. Comunitarias}

Las barreras individuales se han relacionado con un menor desarrollo de las habilidades motoras, problemas de comportamiento, dificultades en el aprendizaje y necesidad de supervisión (en los casos de TEA con mayor afectación). Entre las barreras familiares se han identificado la falta de tiempo y las actitudes, creencias y percepciones de las familias respecto a la AF. Por último, en las barreras comunitarias se han identificado la falta de recursos y de oportunidades (Duquette et al., 2016; Nichols, Block, Bishop y Mclntire, 2019; Scharoun, Wright, Robertson-Wilson, Fletcher y Bryden, 2017).

\section{6}

La familia juega un papel importante en la práctica de AF de sus hijos/as. Por ello, una estrategia efectiva para la promoción de AF en las personas con TEA es realizar programas recreativos que involucren a sus familias (Brown, ArbourNicitopoulos, Martin, Latimer-Cheung y BassettGunter, 2020).

Cabe destacar que las barreras de un tipo pueden influir en las de otro tipo. Por ejemplo, si una persona no tiene oportunidades para hacer AF en su contexto social (barrera comunitaria) tiene menos posibilidades de relacionarse socialmente o de desarrollar su competencia motriz (barreras individuales)

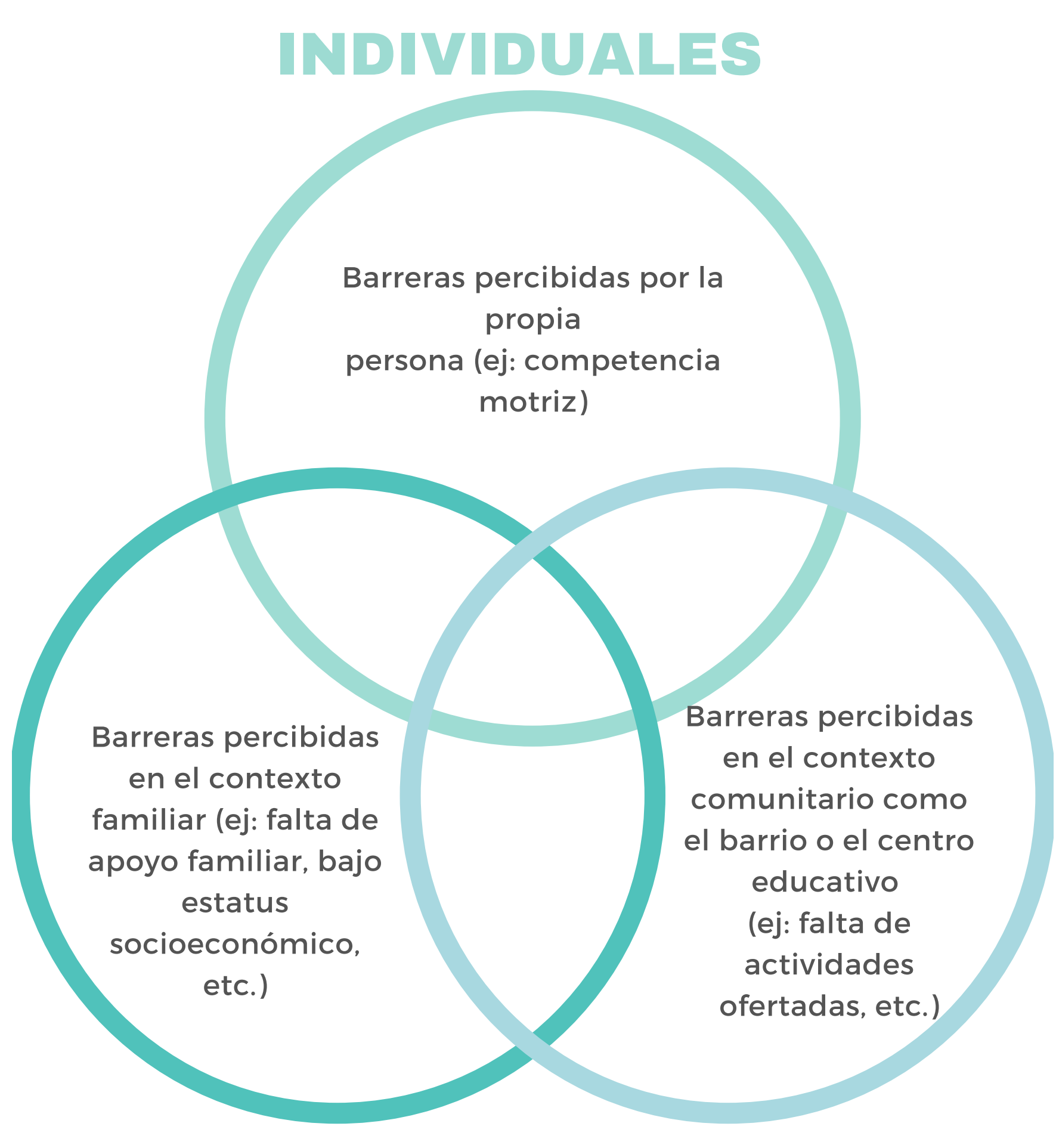

FAMILIARES COMUNITARIAS

Figura 5. Barreras para la práctica de AF en las personas con TEA (modificado de Varin, 2019)

En el contexto físico-deportivo, una persona con TEA puede presentar dificultad para entender y comprender las reglas de un juego o para desarrollar estrategias (Duquette et al., 2016). Del mismo modo, podrian presentar desinterés por determinadas actividades (Nichols et al., 2019). Por otro lado, la necesidad de seguridad y de estabilidad podría limitar su participación ante una tarea nueva o una actividad que se desarrolla en un entorno desconocido. El entorno físico también puede suponer una barrera para la práctica de AF ya que puede afectar a los diferentes órganos sensoriales. Por ejemplo, el tacto de un gorro de baño, el ruido de una piscina mientras se hacen actividades acuáticas o el destello de las luces de un pabellón poli-deportivo podrian resultarles molestos. Estas personas pueden ser muy sensibles a estímulos sensoriales en los sentidos del gusto, olfato, tacto y 
oído (Autismo Diario, 2011).

En el contexto de la EF, un estudio que analizó las barreras percibidas por los estudiantes con TEA durante las clases de EF, determinó que las principales barreras se vinculan con los diferentes agentes que participan en el proceso de enseñanzaaprendizaje (Duquette et al., 2016). Por ejemplo, la relación o interacción con el docente de EF, así como con el resto de compañeros/as, podría favorecer o dificultar las oportunidades de práctica de AF (Figura 6).

En conclusión, todas las acciones dirigidas a la reducción de una barrera podrian incidir de forma positiva en el resto de barreras (cuantas más oportunidades para practicar AF en el centro educativo/barrio [barrera comunitaria] más oportunidades de comunicación y relación social [barrera individual]). Sin embargo, debemos tener en cuenta que no todas las personas tienen las mismas barreras y, por lo tanto, deberá analizarse cada caso de forma individual. Por otro lado, las barreras identificadas, especialmente las relacionadas con el ámbito deportivo-educativo, podrian reducirse a través de estrategias metodológicas específicas.

\section{Docentes}

1. Falta de formación y conocimientos, falta de recursos y estrategias de intervención, actividades muy centradas en la competición y actividades poco inclusivas.

\section{Compañeros/as sin TEA}

2 Intimidación, falta de conocimientos y sensibilización sobre el TEA y comportamientos pocos inclusivos.

\section{Otros}

3 Disponibilidad y tipología de las actividades, transición a la Educación Secundaria Obligatoria y gran estímulación sensorial (ruidos, diferentes texturas, etc.), entre otros.

Figura 6. Barreras percibidas por los estudiantes con TEA en las clases de EF (modificado de Duquette et al., 2016)

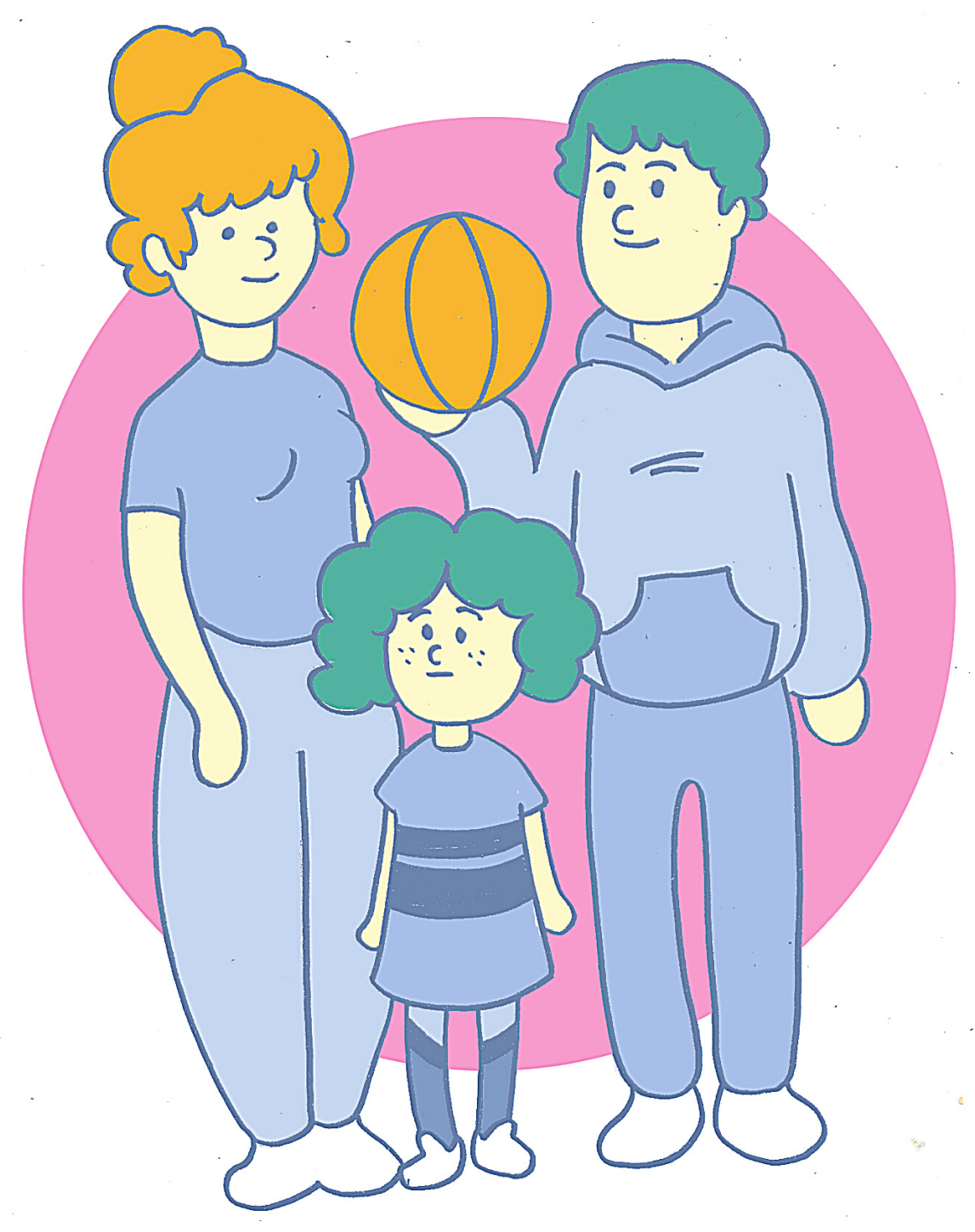

\section{La menor participación en actividades físico-deportivas de los jóvenes con TEA se hace extensible a la etapa adulta. En} la adultez, se ha identificado. entre otras (Hillier, Buckingham y Schena, 2020):

1. Una menor frecuencia en la práctica de AF a una intensidad moderada o vigorosa.

2. Actitudes menos positivas hacia la AF.

3. Mayor dificultad en La realización de AF.

Por lo tanto, resulta fundamental promover la práctica de AF desde edades tempranas a través de experiencias positivas que generen adherencia a la AF. minimizando la competición y diseñando actividades accesibles e inclusivas (Colombo-Dougovito, Blagrave y Healy, 2020; Nichols et al., 2019). 


\section{Estrategias para el diseño de actividades físico-deportivas en personas con Trastorno del Espectro del Autismo}

Todas las personas del ámbito educativo, deportivo - recreativo son educadores, facilitadores y promotores de la práctica de AF. Sin embargo, recientes estudios han evidenciado una falta de formación en el profesorado e instructores de actividades físico-deportivas para diseñar e implementar juegos o deportes para el alumnado con TEA (Duquette et al.,2016; Maher, 2017; SánchezBlanchart, Sánchez-Oliva, Pastor-Vicedo y MartínezMartínez, 2019). Para que las personas con TEA obtengan los beneficios de la AF, parece necesario que los docentes de EF o educadores físicos conozcan estrategias metodológicas específicas que favorezcan la inclusión, la integración y la participación de estas personas (Menear y Neumeier, 2015).

A continuación, se enumeran algunas de las estrategias $u$ orientaciones metodológicas que se han mostrado efectivas para la promoción de AF en esta población (Figura 7):

\section{Individualización}

De manera previa a intervenir con estas personas, parece conveniente conocer sus características indi- viduales puesto que no existen dos personas con TEA iguales. Concretamente, su canal de comunicación y modalidad sensorial preferente (imitación, verbal, no verbal), así como la presencia de comportamientos estereotipados y rasgos de personalidad (preferencia de actividades y materiales). Del mismo modo, parece oportuno conocer aquellos estímulos que les disgustan, las conductas obsesivas (si las hubiera) y sus características motrices (Asún, 2016). Si se tienen en cuenta los intereses, las particularidades sensoriales y las habilidades y caracteristicas motoras del alumnado, será más sencilla su integración en las sesiones de AF (Duquette et al., 2016). Además, la información obtenida de este análisis preliminar guiará la planificación e implementación de las actividades, acorde a sus necesidades, intereses, posibilidades y motivaciones.

Por otro lado, podría ser necesario trabajar las actividades antes de comenzar la sesión de AF. Algunos autores recomiendan el uso de historias o pre-visualizaciones ("vista previa") para mostrar las actividades y las habilidades motoras que se van a trabajar (Grenier y Yeaton, 2011; Menear y Neumeier, 2015). Este método podría anticipar el escenario que el alumnado va a encontrar y, por lo tanto, reducir la

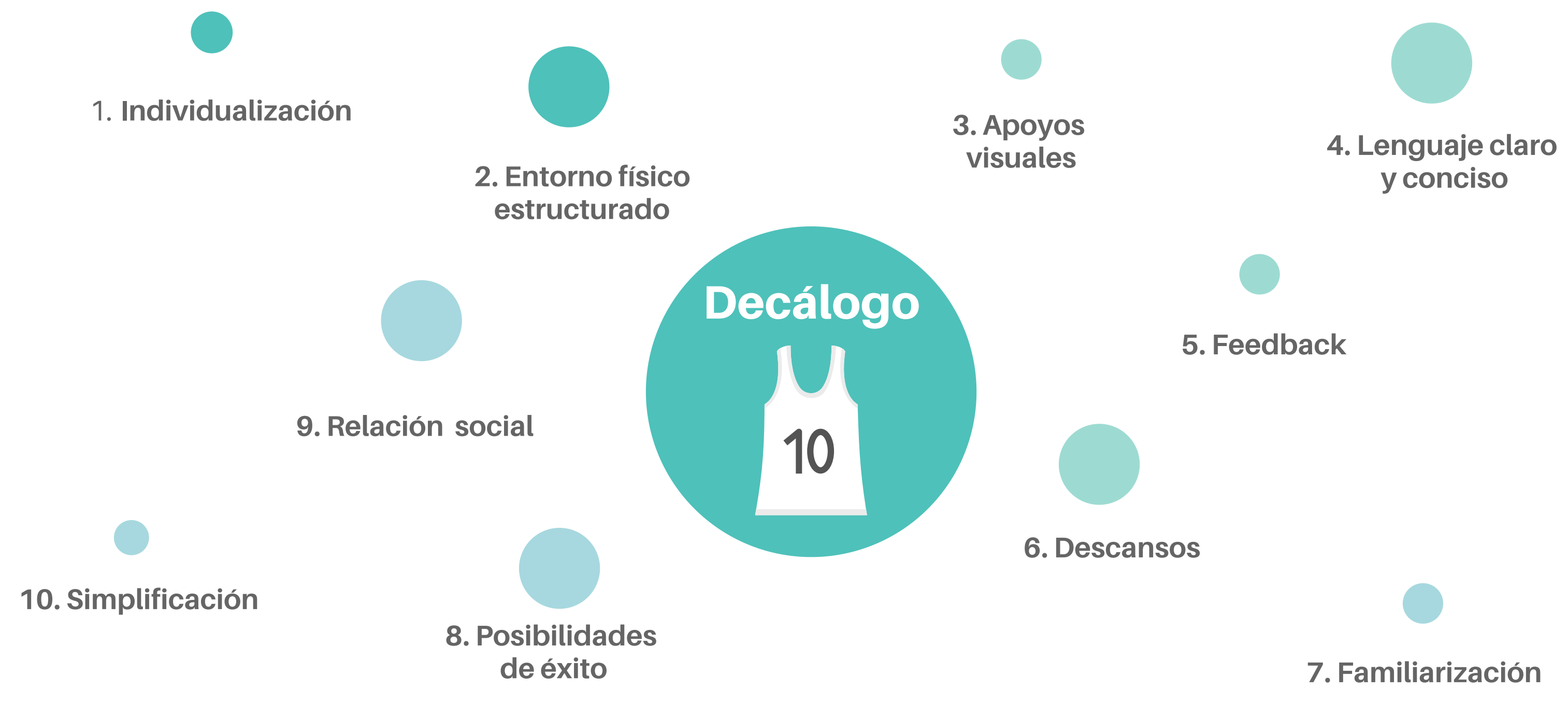

Figura 7. Decálogo de estrategias para la promoción de AF en personas con TEA 
incertidumbre que podría provocarles el desarrollo de una actividad, así como el rol que deben ejercer en la sesión (Gómez et al., 2008).

Además, es recomendable compartir el tipo de actividad que se va a realizar con el grupo-clase (es decir, con el resto de alumnado neurotípico o sin TEA), con objeto de sensibilizarles. Este aspecto es especialmente relevante en

las primeras sesiones en las que se comparta actividad con la/s persona/s con TEA. Para ello, es imprescindible tener la autorización familiar o de la persona que ejerza como tutor legal en su caso, para poder hablar de las características de dicha/s persona/s.

\section{Entorno físico estructurado}

Las personas con TEA necesitan un mundo estructurado y predecible (Asún, 2016; Rivière, 2001). Para ello, parece adecuado tener espacios y rutinas fijas (por ejemplo, un espacio concreto para proporcionar la información inicial, un lugar fijo para dejar los abrigos, una música específica para comenzar la sesión, etc.). Además, parece conveniente elaborar un horario de ejercicio para generar rutinas. Las personas con TEA suelen tener un calendario semanal $u$ hoja de rutinas donde aparecen las actividades que deben hacer cada día (por ejemplo, ir al instituto). Por ello, sería aconsejable incorporar la práctica de AF en su agenda diaria (por ejemplo, las actividades extraescolares de la disciplina deportiva que practiquen, las clases de EF, etc.)(Abarca, 2015; Menear y Smith, 2011; Srinivasan, Pescatello y Bhat, 2014).
Dentro del gimnasio, los materiales deben estar ordenados (Asún, 2016) y el ambiente debe de ser seguro. En las sesiones de EF o actividades físicodeportivas, son frecuentes los cambios continuos de actividades, reglas, agrupaciones, materiales, espacios, etc. Esta circunstancia podría provocar una sobre-estimulación en el alumnado con TEA. Por ello, se debe evitar, en la medida de lo posible, los cambios continuos a lo largo de una sesión y los ambientes caóticos, ya que pueden generar mucha estimulación (Rivière, 2001). Además, las personas con TEA podrian presentar hipersensibilidad a la luz o al ruido (a veces, reciben todos los sonidos a la vez y no son capaces de filtrarlos). Por ejemplo, en un deporte de colaboración-oposición como el baloncesto se produce mucho ruido por los continuos botes del balón con el suelo o mucha incertidumbre por la presencia de compañeros y adversarios. En consecuencia, podrian aparecer conductas auto-estimulantes o disruptivas (Gómez et al., 2008; Srinivasan, et al., 2014) para canalizar su frustración o ansiedad, por lo que no deben interpretarse como algo personal. En este sentido, algunos autores señalan que los deportes de colaboración-oposición podrían no ser los más adecuados con esta población ya que la alta incertidumbre que existe en este tipo de actividades podría limitar sus posibilidades de participación (Simpson, Gaus, Biggs y Williams, 2010). Sin embargo, el profesorado de EF y/o los educadores físico-deportivos deberán valorar la inclusión de estos deportes en las sesiones en función de las caracteristicas específicas de las personas con TEA.

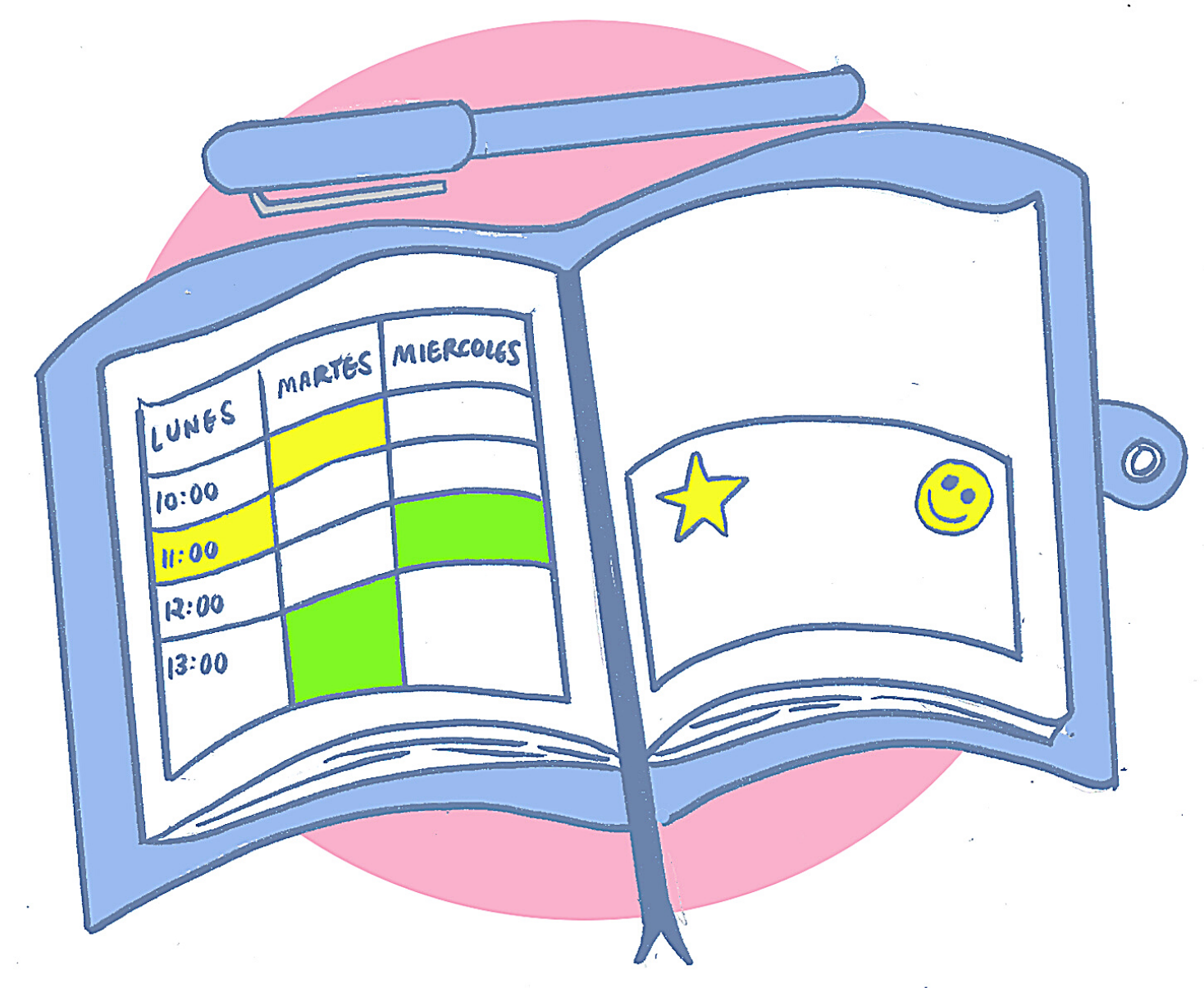




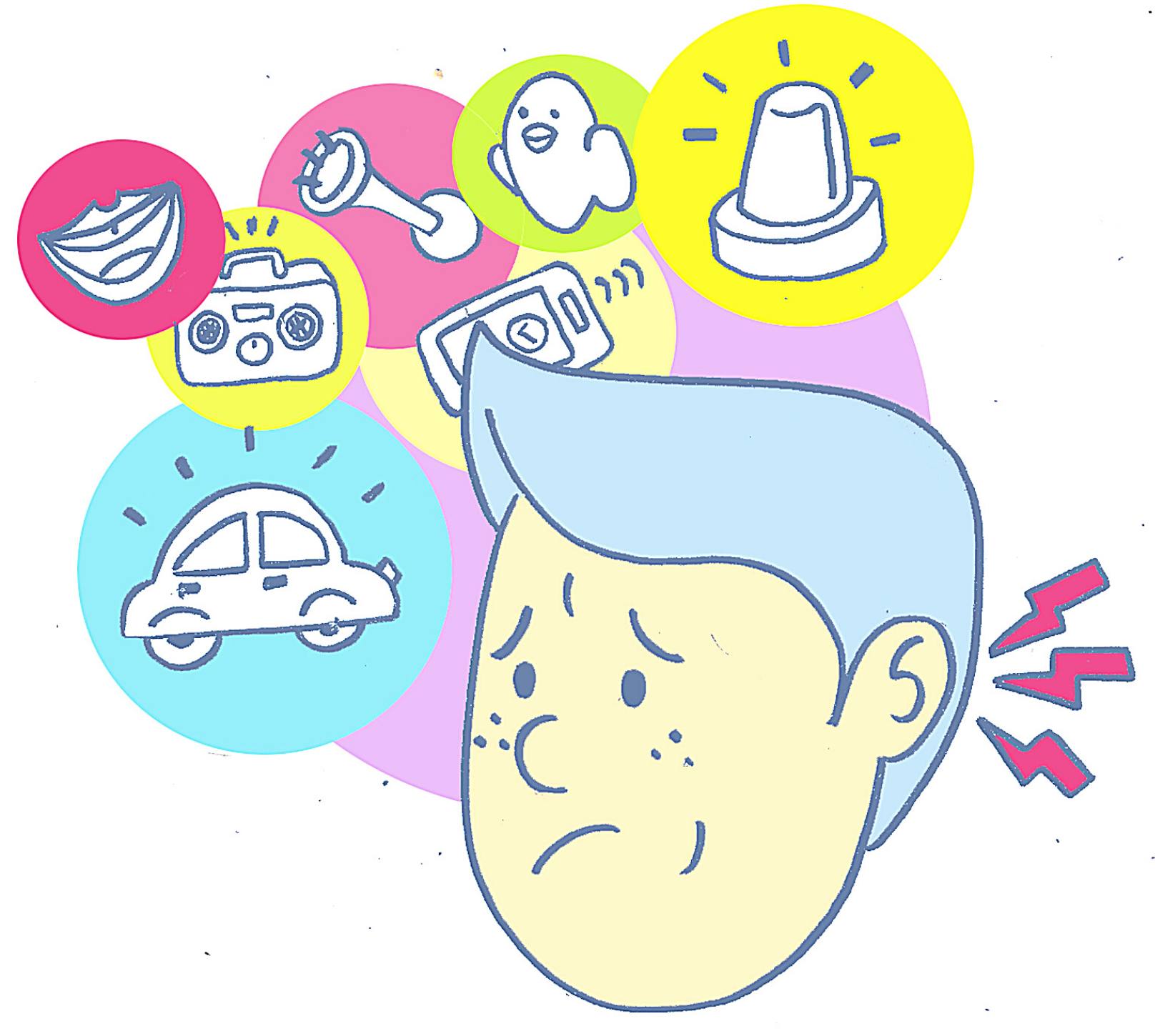

Si durante la sesión de AF un alumno/a con TEA presenta una estereotipia sería aconsejable eliminar o reducir el elemento que le resulta estresante. Además, se podría intentar reorientar su atención. Por ejemplo, a través de alguno de sus objetos preferidos (Autismo Madrid, 2013). Es importante al respecto:

1. Conocer bien al alumnado.

$$
\text { 2. Ser respetuosos y }
$$
pacientes cuando muestren comportamientos repetitivos.

3. Tener interés por explorar que es lo que se vincula a esa expresión estereotipada, es decir, si viene producida por una sobrexcitación, una autoestimulación o un malestar.
Por otro lado, se debe de controlar el acceso a los materiales y conocer si algunos de estos les producen una sobre-estimulación (por ejemplo, si a una persona le produce una excitación una pelota, evitaremos que la utilice durante la sesión). Se aconseja disponer exclusivamente del material que se requiere para llevar a cabo la actividad. Esta premisa contribuye a reducir el número de elementos distractores y favorece que se mantenga la atención en la tarea (Simpson et al., 2010). Autores como Staples, Todd y Reid (2006) recomiendan cerrar la puerta del gimnasio o no hacer uso del silbato para disminuir los estimulos durante las sesiones de AF en las personas con TEA.

Asimismo, parece adecuado establecer un espacio dentro del pabellón o gimnasio con menor ruido para las personas con TEA. Normalmente, es preferible utilizar el perímetro del pabellón o del gimnasio respecto a la parte central (Simpson et al., 2010). Este espacio es denominado por algunos autores como espacio de escape o área tranquila (Martin, 2016).

\section{Apoyos visuales}

En las sesiones de AF pueden exponerse, previamente y de manera gráfica, las partes de la sesión (calentamiento, parte principal y vuelta a la calma o estiramientos), los materiales que van a utilizarse en cada actividad (por ejemplo, una cuerda) e, incluso, la acción a realizar (por ejemplo, lanzar). En algunos casos, las imágenes pueden ir acompañadas de descripciones escritas en la parte superior (Fittipaldi-Wert y Mowling, 2009).

Es necesario resaltar que el uso de los soportes visuales debe adaptarse a las necesidades de cada alumno/a y, si es posible, deben estar asesorados por profesionales de referencia. En este sentido, algunos autores recomiendan que la implantación de los mismos sea progresiva y que únicamente incluya información relevante (Fittipaldi-Wert y Mowling, 2009). 
En relación a los apoyos visuales, también puede ser adecuado disponer de un temporizador o reloj en la pared que permita conocer el tiempo de la clase y/o actividad (Menear y Neumeier, 2015; Menear y Smith, 2011; Rivière, 2001). Saber cuándo acaba una tarea/clase les facilita la transición a la siguiente.

Por último, es importante utilizar todos los canales de comunicación simultáneamente (Rivière, 2001). Aunque muchas de las personas con TEA tienen una modalidad sensorial preferente (normalmente la visual; Abarca, 2015; Fittipaldi-Wert y Mowling, 2009), el canal verbal y visual (por ejemplo, a través de demostraciones) pueden ser complementarios (Srinivasan et al., 2014). En las sesiones de AF, podemos encontrar estudiantes con dificultades para comprender la explicación de una tarea pero con gran capacidad de imitación (Fernández, 2011)

Como se ha comentado con anterioridad, en el caso de utilizar apoyos visuales o SAAC, sería recomendable trabajar con los profesionales de referencia.

Las personas de referencia son los terapeutas

(logopedas, psicólogos/as, etc.) docentes especialistas (audición y lenguaje [AL], pedagogía terapeútica [PT], etc.), familia, y cualquier profesional que pueda ser el principal articulador de la intervención en SAAC.

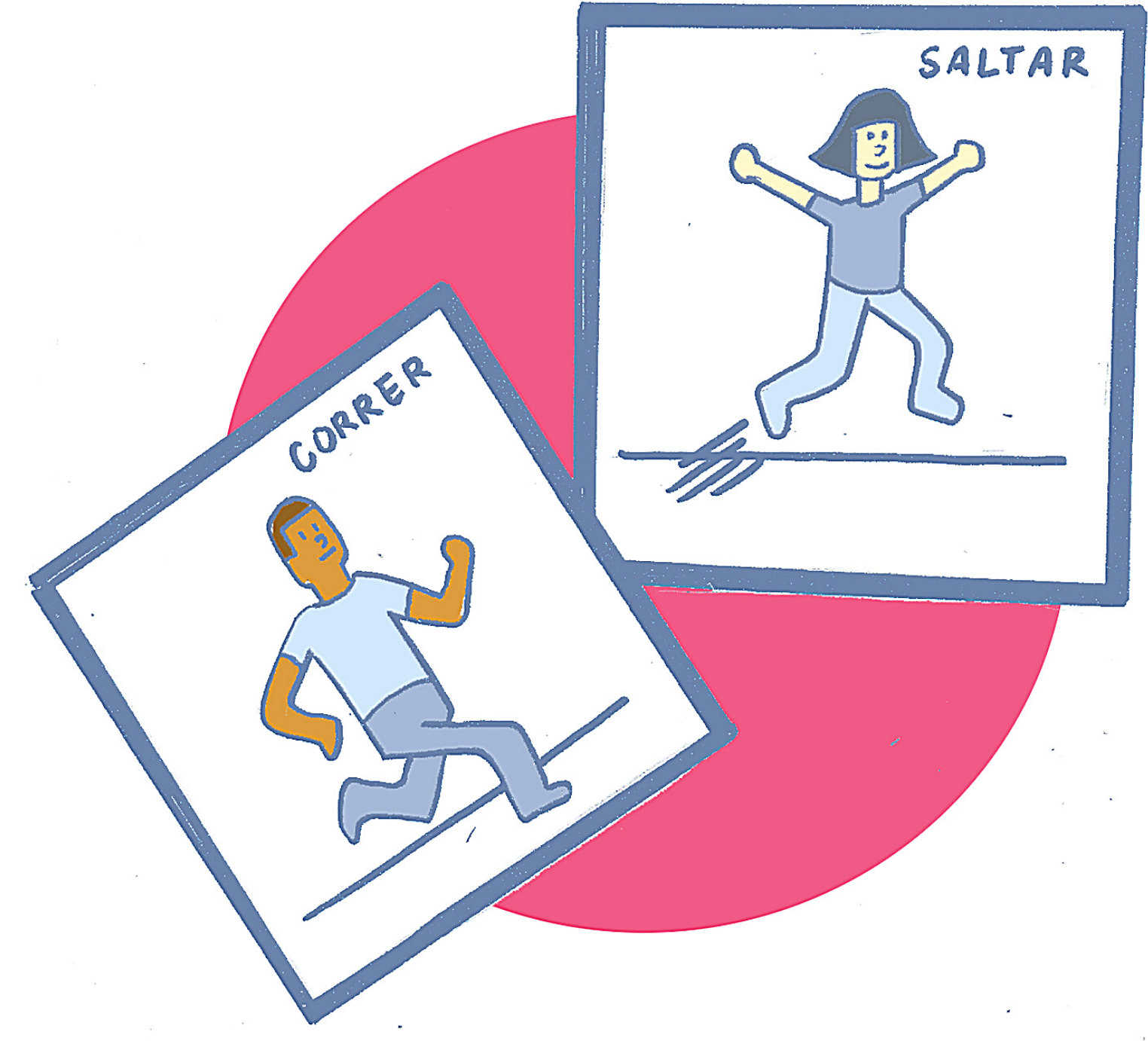

4 Lenguaje claro y conciso

Se deben evitar largas explicaciones en los ejercicios. Las instrucciones deben de ser claras y con un estilo de comunicación conciso y sencillo (Rivière, 2001; Simpson et al., 2010; Srinivasan et al., 2014). Además, el grado de conocimiento de la tarea debe de ser progresivo (Asún, 2016). Para ello, puede desglosarse una tarea en diferentes fases con objeto de ofrecer las explicaciones de forma secuencial.

Por otro lado, es importante tener en cuenta que las personas con TEA podrian tener un vocabulario limitado. Además, pueden tener dificultades para comprender la ironía, el sarcasmo o las expresiones ambiguas (Reid, O'connor y Lloyd, 2003). Por ello, cuando se proporcione información parece necesario hacer uso de un vocabulario sencillo, sin ambigüedades (Staples et al., 2006). En la Figura 8 se especifican algunas estrategias para reducir las barreras en la comunicación (Duquette et al., 2016). 


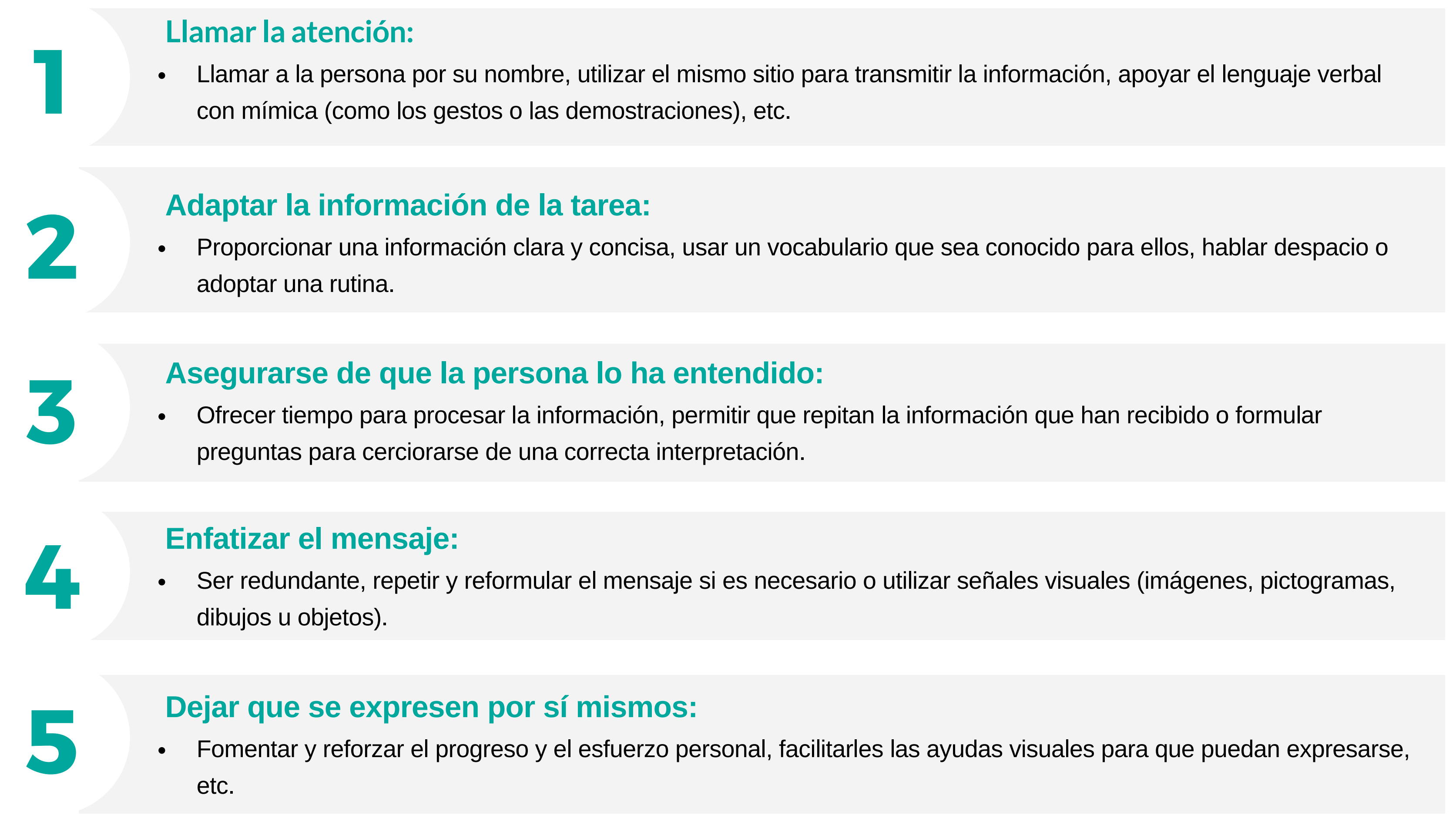

Figura 8. Estrategias para reducir las barreras en la comunicación (modificado de Duquette et al., 2016)

\section{Feedback}

Durante el desarrollo de las actividades deben limitarse las ayudas excesivas (Rivière, 2001). Asimismo, es importante proporcionar un feedback que motive o elogie a los participantes (Gómez et al., 2008; Rivière, 2001). Sin embargo, no debe de ser demasiado recurrente ya que podría provocar una sobre-estimulación en los estudiantes con TEA.

En este sentido, los feedback deben de ser significativos, privados y centrados en el proceso. De igual modo, son importantes los feedback descriptivos que le ayuden a entender los movimientos que ha realizado en el desarrollo de una tarea. Por ejemplo, el mensaje "bien hecho" es menos específico en comparación con "buen salto y aterrizaje con los dos pies" (Reid et al., 2003). Se pueden aprovechar algunos espacios como, por ejemplo, la espera del turno en un circuito o en una actividad para introducir, progresivamente, explicaciones al alumnado con TEA. Por otro lado, parece adecuado reforzar el progreso, especialmente, en aquellos elementos en los que tiene más dificultades. Por ello, se reforzarán las re- laciones sociales adecuadas y la adquisición de nuevas habilidades motrices (Simpson et al., 2010).

Además, parece necesario ofrecer los feedback desde una perspectiva positiva. Por ejemplo, si queremos corregir alguna acción, podría emitirse la información de la siguiente forma: "Me encanta como saltas, pero recuerda que si aterrizas con los dos pies conseguirás más equilibrio. Ánimo con el siguiente intento, ya verás cómo poco a poco saldrá mejor" (Staples et al., 2006).

\section{Descansos}

Las personas con TEA suelen fatigarse con mayor intensidad y periodicidad (tanto física como mentalmente), por lo que puede ser adecuado planificar un descanso extra en estas personas durante el transcurso de las actividades o en la finalización de las mismas. Del mismo modo, debe prestarse atención a las necesidades básicas que puedan presentar: sed, calor, frío, etc. (Gómez et al., 2008). Además, algunas personas con TEA tienen insensibilidad al dolor (por ejemplo, un balonazo). Esta característica requiere que se preste atención a su integridad física (Gómez et al., 2008). 
En los descansos pueden realizar alguna actividad sensorial que les resulte gratificante o estar con su juguete u objeto favorito (Srinivasa et al., 2014).

\section{Familiarización}

En primer lugar, es necesaria una familiarización con el entorno. Este proceso podría conllevar desde varios minutos hasta varias clases (Staples et al., 2006).

Por otro lado, las personas con TEA pueden requerir un tiempo más prolongado para procesar nuevas informaciones y retener nuevas habilidades. Por ello, se debe de proporcionar el tiempo necesario para que puedan adaptarse y familiarizarse con los ejercicios y los roles que aparecen en cada actividad (Srinivasan et al., 2014). Por ejemplo, en una actividad con cambios de roles constantes como pasar de ser atacante a ser defensor (Menear y Neumeier, 2015). Asimismo, se debe proporcionar un tiempo para conocer $y$ familiarizarse con el docente o los compañeros/as (Reid et al., 2003).

\section{Posibilidades de éxito}

Se recomiendan actividades variadas (Srinivasan et al., 2014) donde puedan sentirse competentes y con posibilidades de éxito (Rivière, 2001; Srinivasan et al., 2014). Del mismo modo, las actividades deben de ser acordes a su nivel de desarrollo psicomotor y edad cronológica (Menear y Neumeier, 2015; Rivière, 2001). Por lo tanto, es necesario encontrar el equilibrio para que una actividad pueda desarrollarse con éxito (objetivos alcanzables) y, a su vez, sea motivante (Abarca, 2015).
$\mathrm{Si}$ las personas con TEA tienen experiencias satisfactorias en las actividades que realizan, existen más probabilidades de que quieran seguir realizándolas en futuras ocasiones. Para ello, las actividades pueden sufrir pequeñas adaptaciones para que mantengan el reto y el desafio (por ejemplo, ante una misma actividad, modificar el tamaño del móvil, los implementos, etc. ) (Staples et al., 2006)

Aunque el diseño de actividades con posibilidades de éxito para todo el grupo-clase puede suponer un desafio para el docente, la modificación de algunos elementos como las reglas, el móvil, el espacio o el número de jugadores podrian favorecer la consecución de este objetivo. Por ejemplo, si se practica el lanzamiento/puntería, algunos estudiantes podrían trabajarlo con un determinado móvil, diferente distancia, diferente zona de impacto, etc. Por tanto, no es necesario que todo el alumnado realice una tarea de forma idéntica para trabajar un mismo contenido (Staples et al., 2006).

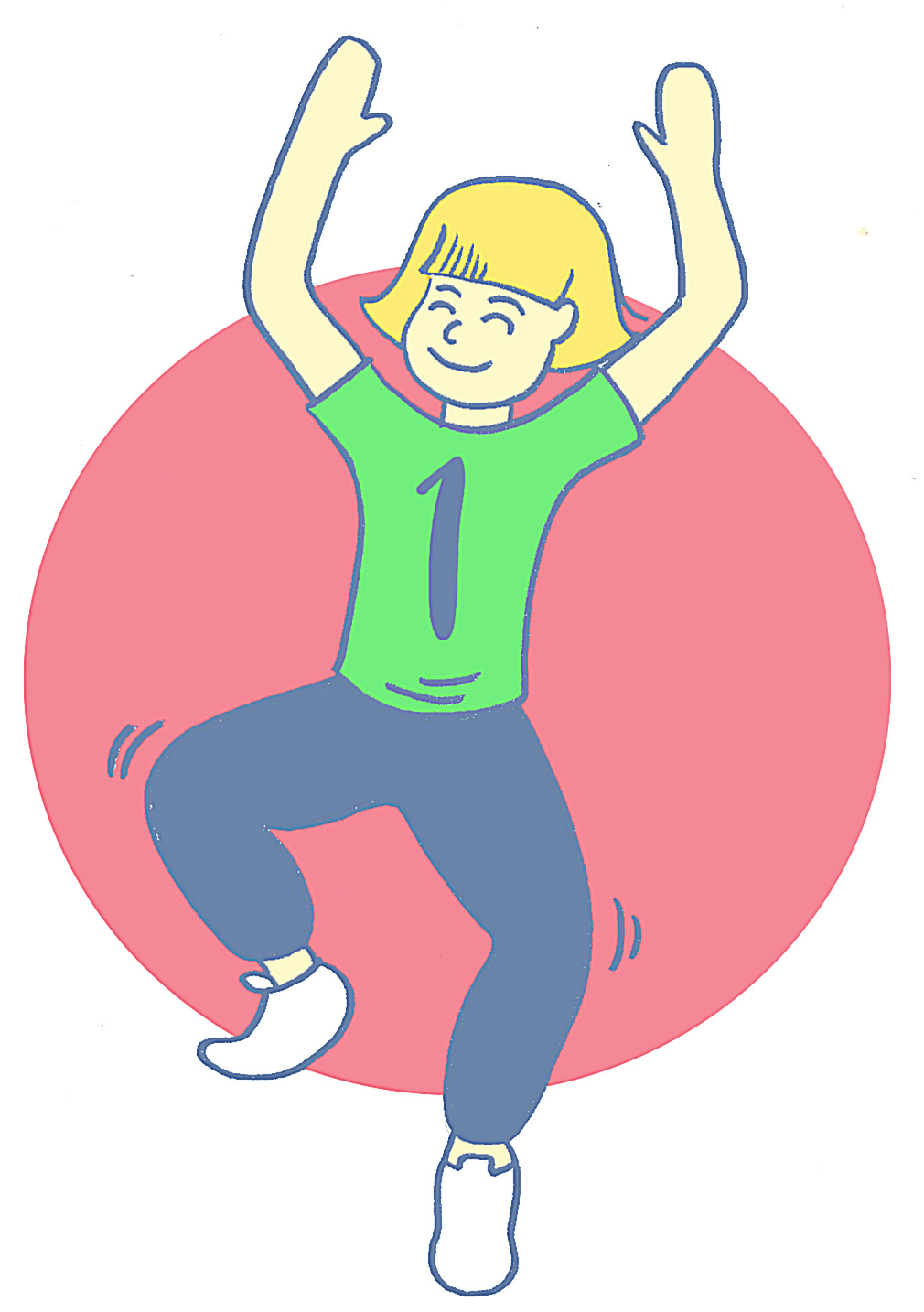

Si generamos experiencias satisfactorias en las personas con TEA será más probable que continúen realizando $A F$ en su vida adulta (ColomboDuogovito et al., 2020). 


\section{Relación social}

Las actividades con algún compañero/a (por ejemplo, realizar ejercicios por parejas) pueden resultar estimulantes para algunos niños/as (Srinivasan et al., 2014). En este sentido, parece necesario anticiparles el contacto: "voy a cogerte de la mano para realizar esta actividad" (Reid et al., 2003). Sin embargo, dado que algunas personas pueden reaccionar de forma diferente al contacto, se deben plantear objetivos sociales que favorezcan progresivamente las relaciones sociales. Por ejemplo, un juego individual, un juego por parejas, un juego en pequeños grupos, etc., incrementándose el número de personas en las agrupaciones (Asún, 2016). También podrían utilizarse materiales que favorezcan que no exista un contacto directo con sus compañeros/as. Por ejemplo, en lugar de ir cogidos de la mano, pueden ir cogidos mediante un aro u otro material que les resulte agradable (Staples et al., 2006).

Plantearse objetivos en el área social es especialmente importante en el desarrollo de las actividades. Algunos estudios han revelado mayor soledad y peor calidad en las relaciones de amistad en las personas con TEA en comparación con sus homólogos neurotípicos. Por lo tanto, las actividades que favorezcan las relaciones sociales y el contacto parecen especialmente necesarias en estas personas (Locke, Ishijima, Kasari y London, 2010). Simplemente compartir un espacio o un equipamiento (como, por ejemplo, escalar en las es-

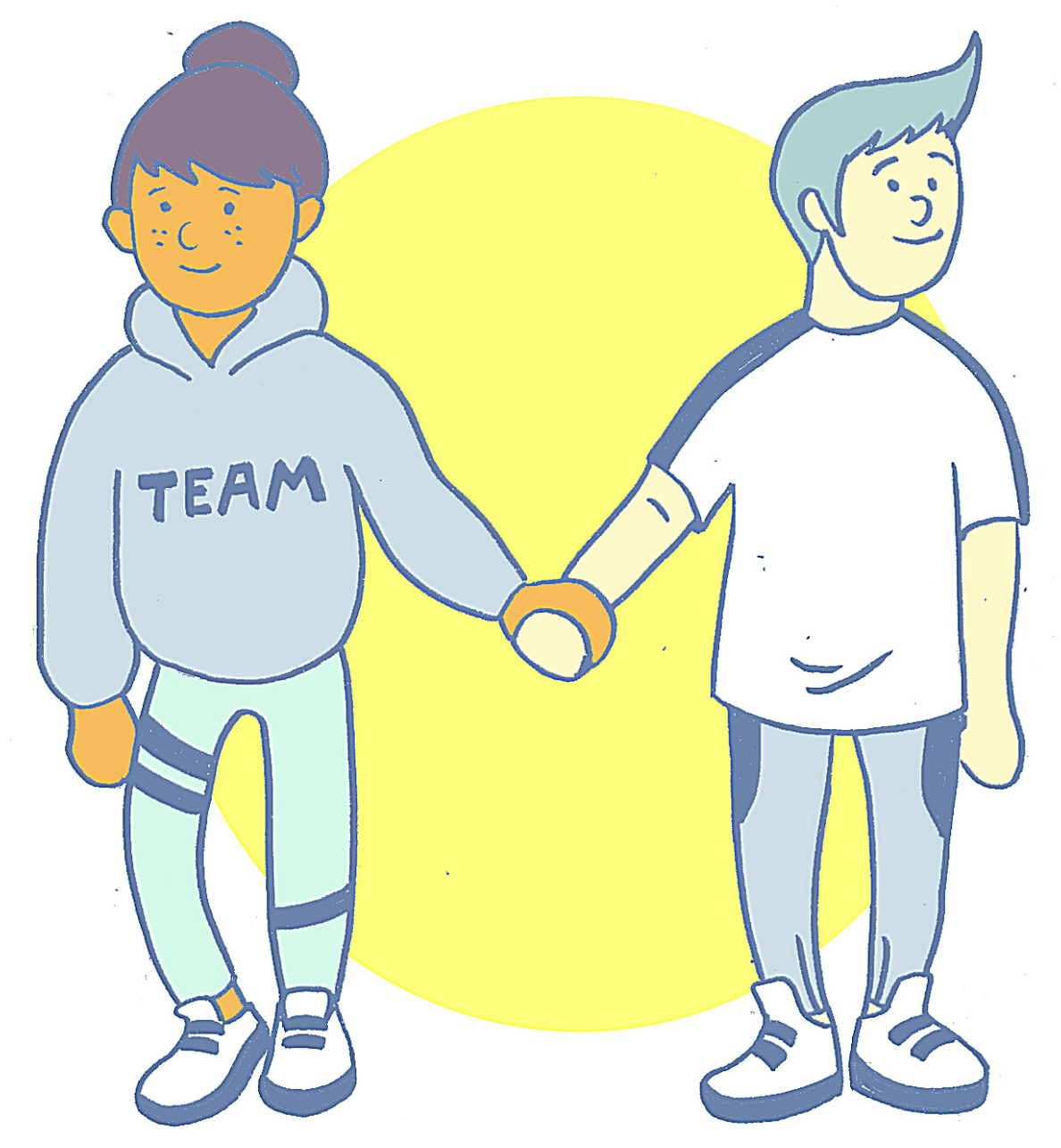

palderas), jugar por parejas o aprender a perder de forma agradable son aspectos beneficiosos para estas personas (Reid et al., 2003). En este sentido, aunque el estudio desarrollaro por Heredia y Duran (2017) reveló una alta participación del alumnado con TEA en actividades individuales (por ejemplo, correr) y cooperativas (por ejemplo, jugar al paracaídas), el grado de interacción fue más alto en estas últimas. Este mismo estudio demostró que las actividades donde se ayuda o se guía al estudiante promueven la inclusión. Por ello, el aprendizaje cooperativo, donde el alumnado se ayuda de forma mutua, podría facilitar la participación e integración. Del mismo modo, una reciente investigación concluyó que las actividades grupales podrian disminuir el aislamiento, favorecer la integración y mejorar las habilidades sociales en las personas con TEA (Aniszewski, 2020). No obstante, la elección de una u otra actividad dependerá de las características de cada persona. En aquellas personas con un mayor grado de afectación se podrian realizar actividades individuales y más analíticas y, en aquellas con menor grado de afectación, actividades cooperativas o grupales (Srinivasa et al., 2014).

Cuando hablamos de integración debemos tener en cuenta el Real Decreto

Legislativo 1/2013, de 29 de noviembre, por el que se aprueba el texto refundido de la Ley General de derechos de las personas con discapacidad y de su inclusión social.

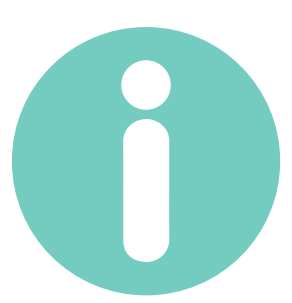

Real Decreto Legislativo 1/2013, de 29 de noviembre.

https://www.boe.es/eli/es/rdlg/2013/11/29 $/ 1 /$ con 


\section{Simplificación de las actividades}

Las personas con TEA podrian presentar alguna dificultad en la motricidad, por lo que podrian percibirse menos competentes motrizmente en tareas muy complejas o excesivamente competitivas. Además, a la hora de programar y secuenciar correctamente las actividades, es necesario conocer el nivel de competencia motriz del alumnado (Abarca, 2015). En este sentido, es muy importante reforzarles de forma positiva cada vez que progresen en el desarrollo de una competencia o habilidad (Asún, 2016).

Una manera de simplificar las actividades y favorecer la adquisición de habilidades de forma secuencial podría ser mediante circuitos. La realización de sesiones a través de estaciones ha demostrado ser efectiva en los contextos físicodeportivos con personas con TEA, probablemente, por tratarse de espacios estructurados con actividades con un principio y un final muy marcado. Sin embargo, la preparación de estos debe de ser minuciosa (Ruiz et al., 2015). Previo a su implementación, parece necesario trabajar los turnos, la colaboración y la espera (Gómez et al., 2008; Fernández, 2011). Para ello, la colocación de tiras adhesivas en el suelo para indicar la espera (a través de figuras o símbolos de pies; Gómez et al., 2008) y la presentación de tarjetas $u$ otros elementos visuales donde se indiquen las actividades a realizar facilita la comprensión de la tarea. Además, las diferentes estaciones podrian estar conectadas en el suelo a través de cuerdas o marcas, para no perder la continuidad (Gómez et al., 2008)

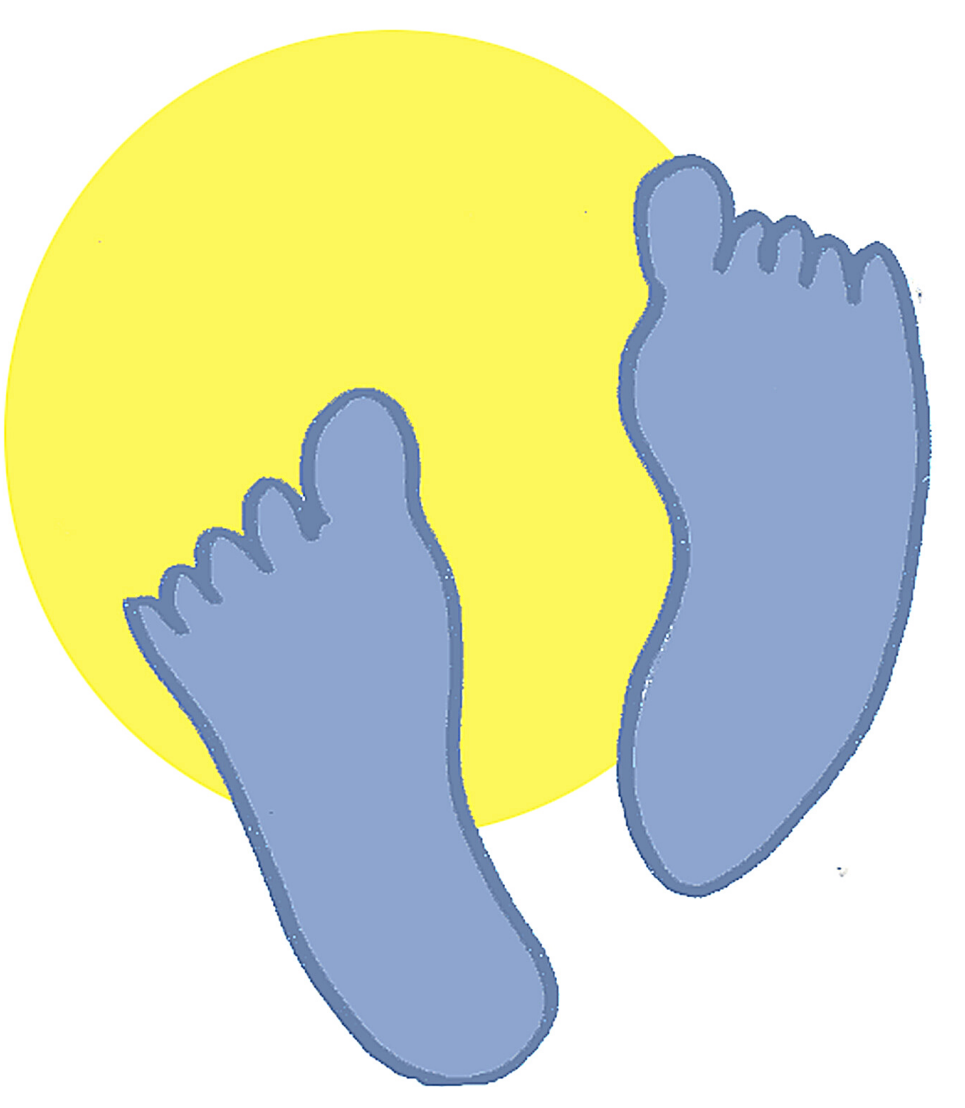

Por otro lado, parece necesario tener en cuenta las capacidades y habilidades específicas de cada persona. De este modo, podemos otorgar al alumnado con TEA algún rol secundario dentro de su propio grupo. Por ejemplo, imaginemos que en la sesión/clase hay una persona con TEA extremadamente hábil en operaciones matemáticas. Las actividades físico-deportivas podrian combinarse con retos académicos (Simpson et al., 2010) y, ante una actividad de lanzamientos, podría calcular el porcentaje de aciertos y/o errores.

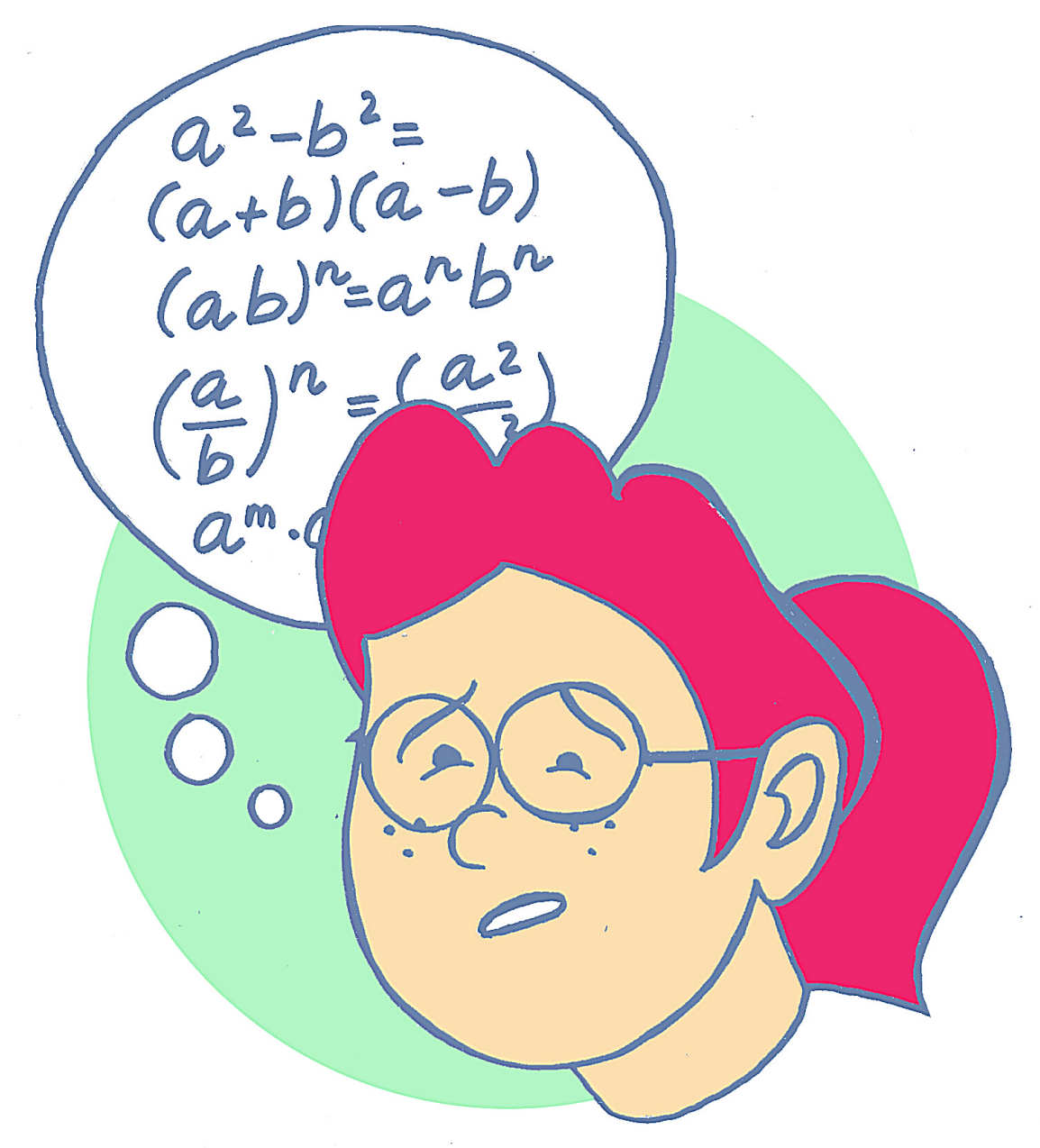

En definitiva, en el proceso de enseñanzaaprendizaje de las personas con TEA se debe tener en cuenta que cada una de ellas es diferente. Lo que puede ser práctico y funcional para una persona puede no resultarlo para otra, generando diferentes efectos en cada participante (Aniszewski et al., 2020). Por ello, las diez estrategias metodológicas presentadas deben individualizarse en función de las características y los objetivos de cada estudiante. Dado que personalizar cada recurso metodológico supone un gran desafío para los docentes, es recomendable trabajar con los profesionales de referencia para desarrollar los apoyos visuales, las rutinas, las metas o los objetivos, en función de las necesidades de la persona (Fittipaldi-Wert y Mowling, 2009). Del mismo modo, es imprescindible la implicación y el apoyo de las familias ya que conocen mucho mejor a sus hijos/as (Heredia y Duran, 2017). Además, es importante que el educador físico se familiarice con estas dinámicas, rutinas, sistemas de comunicación, etc. para su correcta aplicación y normalización en el aula (Gómez et al., 2008). 


\section{Metodología TEACCH}

En este epígrafe parece oportuno explicar una de las metodologías más conocidas para trabajar con las personas con TEA.

La metodología TEACCH (Treatment and Education of Autistic related Communication Handicapped Children) es un método de estructuración del ambiente para hacer el entorno más comprensible. Este programa educativo ha sido muy utilizado en personas con TEA por sus efectos positivos en las áreas afectadas (Sanz-Cervera, FernándezAndrés, Pastor-Cerezuela y Tárraga-Mínguez, 2018). Tal y como establece Autismo Diario (2011) y Sanz-Cervera et al. (2018) los principales enfoques del programa son (Figura 9):

1. Estructura física del entorno: supone limitar el espacio, favorecer el acceso a materiales y minimizar los elementos distractores (tanto visuales como auditivos). De esta forma, se facilita el saber qué tienen que hacer y dónde deben dirigirse, promoviendo la autonomía. Además, en esta estructuración física se destina un espacio para la tranquilidad o para poder acudir cuando algún estímulo les resulte molesto.

2. Agendas diarias: las personas con TEA necesitan un ambiente previsible y claridad en la información. Las agendas diarias proporcionan orden, rutina e independencia. A través de imágenes, dibujos u otros apoyos visuales se presentan las tareas que deben realizar en un día (por ejemplo, ir a la clase de EF, ir al entrenamiento del deporte que practican, etc.) y se facilita la transición de un lugar a otro.

3. Sistemas de trabajo: permite secuenciar las actividades, el espacio y el tiempo dedicado a cada una de ellas (por ejemplo, en la clase de EF: calentamiento [5 minutos]). Se trabaja a través de representaciones visuales (en función del alumno/a se utilizarán fotografias, objetos, símbolos, etc.) y, a través de ellas, se aprenden expresiones y nexos como "primero...", "luego...." y "acabado", lo cual les ayuda a cambiar de tarea.

4. Estructuras e información visual: hace referencia a la organización visual (cómo se organiza el material), la claridad (cómo captar la atención para que se preste atención a la información más relevante) y las instrucciones visuales (cómo se transmite la información para que el estudiante realice la tarea). Estas estructuras e informaciones favorecen la comprensión y fomentan la autonomía.

El nivel de estructuración será diferente para cada persona con TEA. Por ello, resulta imprescindible conocer cómo interaccionan y comprenden el entorno, asi como las capacidades y dificultades de cada persona (Sanz-Cervera et al., 2018).
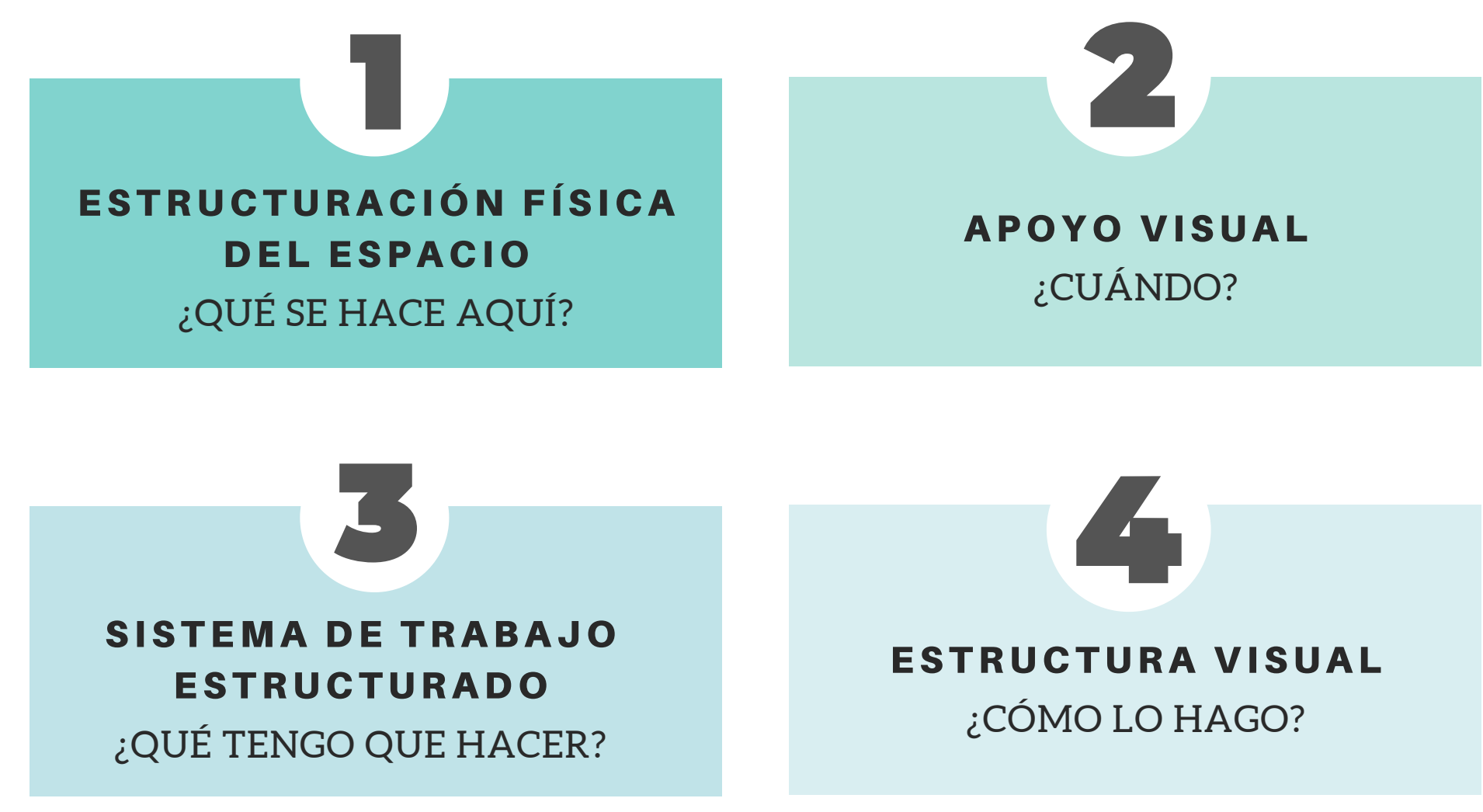

Figura 9. Metodología TEACCH

(modificado de Asociación Navarra de Autismo)

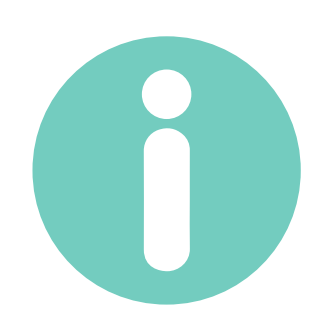

Para más información sobre la
metodología TEACCH
consultar la página de Autismo
Diario y el programa TEACCH:

https://autismodiario.com/gener all

https://teacch.com/ 


\section{Experiencia deportiva y recreativa con Asociación Autismo Huesca}

\subsection{Descripción de la experiencia}

A continuación, se ofrece una experiencia deportiva, recreativa e inclusiva desarrollada en la Facultad de Ciencias de la Salud y del Deporte (Universidad de Zaragoza, Campus de Huesca) (Simón-Montañés, Pastor y Viñas, 2019). Un total de 23 personas pertenecientes a Asociación Autismo Huesca y Universidad de Zaragoza, con edades comprendidas entre los 12 y 37 años, participaron en la actividad. Hasta seis personas presentaban rasgos de TEA con diversos niveles de autonomia y heterogeneidad en los canales de recepción y emisión de la información (verbales, no verbales, etc.). Asimismo, presentaban diferencias en el umbral de estimulación y relación social. Por otro lado, dos profesionales de dicha Asociación supervisaron y apoyaron a las personas con menor autonomía. Los 15 participantes restantes eran estudiantes neurotípicos de la asignatura "Actividad física y deporte adaptado a las personas con discapacidad" del Grado en Ciencias de la Actividad Física y del Deporte (Figura 10)

Para su desarrollo, fueron necesarios tres dinamizadores. Una de ellas, la portavoz, dirigió cada una de las actividades diseñadas. Otra persona se encargaba de la retirada del material tras cada tarea. La última gestionó el tiempo, las puntuaciones y apoyaba al compañero en la gestión y recogida de los materiales. Los roles de estos dinamizadores permanecieron estables a lo largo de la sesión.

Siguiendo las pautas establecidas para el diseño de circuitos (Gómez et al., 2008; Ruíz et al., 2015; Fernández, 2011), se diseñó una Gymkana de Habilidades Motrices Básicas. La actividad incluyó seis pruebas con una duración total de 60 minutos (Tabla 1).

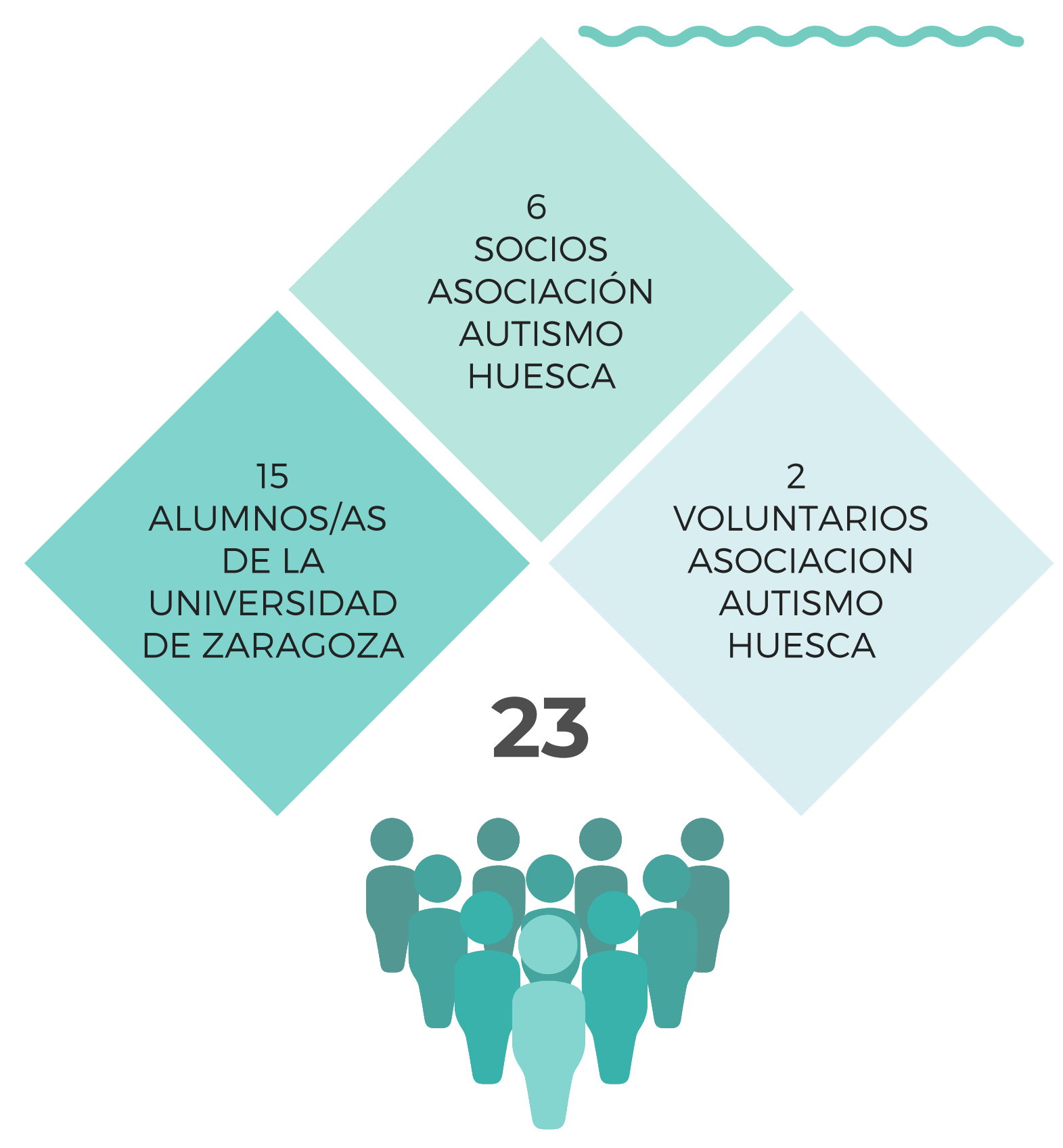

Figura 10. Asistentes a la experiencia práctica

Los asistentes se organizaron en cuatro grupos mixtos y heterogéneos de cinco a seis personas. Los participantes comenzaban cada prueba cogidos de la mano, formando filas de dos en dos. Tras la explicación de la prueba, y una vez dada la señal de inicio, la primera pareja de cada grupo se dirigía hasta el lugar donde se realizaba la prueba, espacio delimitado con figuras en el suelo (a través de dos pies, indicando la necesidad de parar). Una vez allí, disponian del material pertinente para llevar a cabo el reto. Todos los equipos hacian la misma prueba a la vez, cada uno en su espacio. Finalizada la prueba (encestar un aro, transportar un objeto, etc.) cada pareja volvía a la fila de su equipo y, chocándose la mano, daban la salida a la siguiente pareja. Así, sucesivamente, hasta que finalizaba el tiempo destinado a cada reto. 
Tabla 1. Descripción de las pruebas

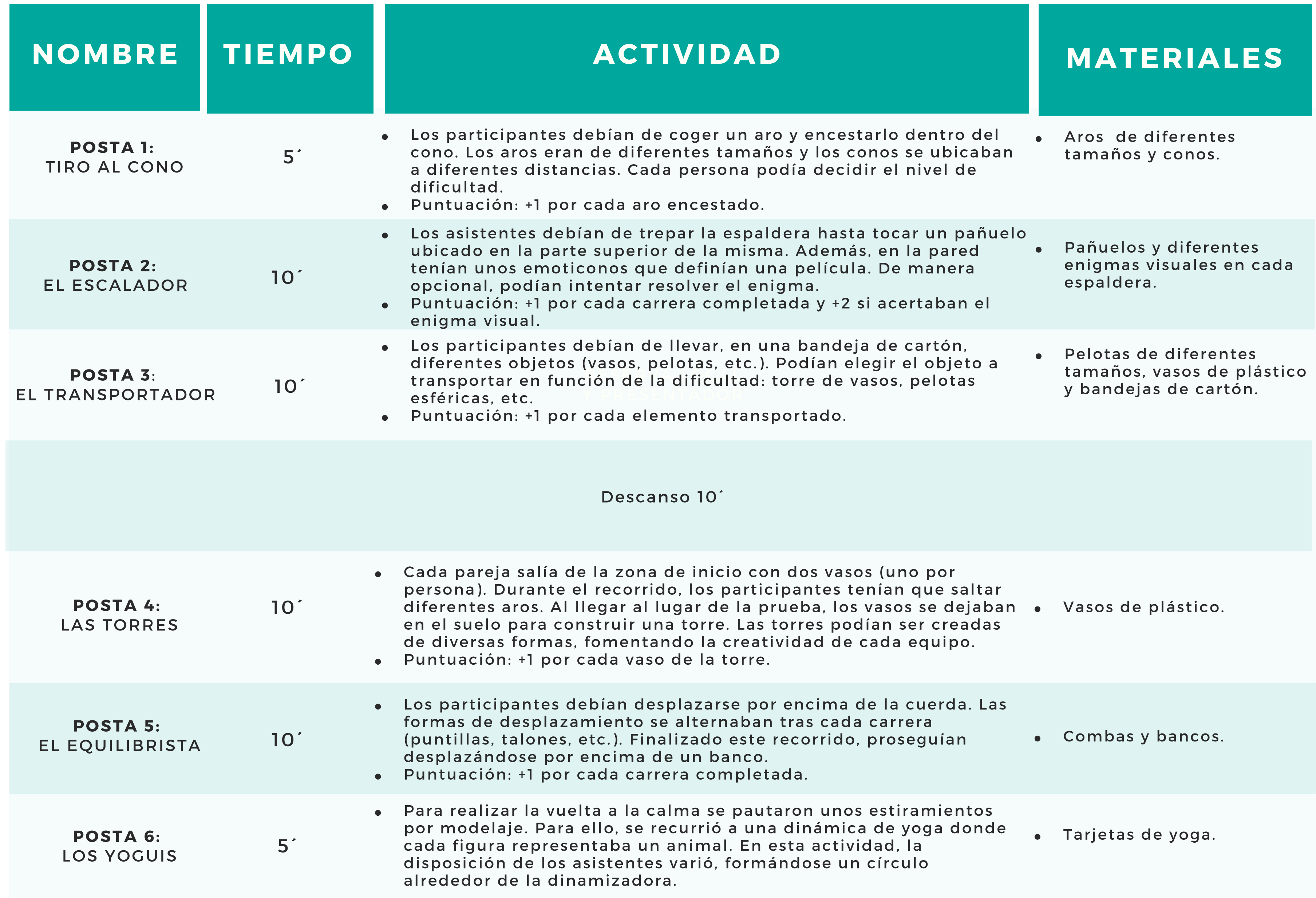

Cada participante que completaba la prueba (encestar un aro, transportar un objeto, etc.), sumaba un punto para su equipo. Al finalizar cada prueba, los puntos de todos los equipos eran sumados. Esta acción se repetía tras cada reto para, finalmente, obtener el sumatorio total. El objetivo era que, entre todos los equipos, se superase una puntuación consensuada de manera previa a la sesión. Este reto disminuyó la competición entre los equipos y permitió que todos los participantes trabajaran de forma conjunta para lograr el objetivo colectivo.

En relación al espacio, se reservó una parte del Pabellón Polideportivo con poco ruido y menor afluencia de personas. El espacio fue sistemático, estructurado e invariable (Figura 11). Los equipos se organizaron mediante cuatro colores, los cuales coincidian con los símbolos ubicados en el suelo. Además, cada persona llevaba un cartel con el nombre del equipo para favorecer y facilitar la interacción.

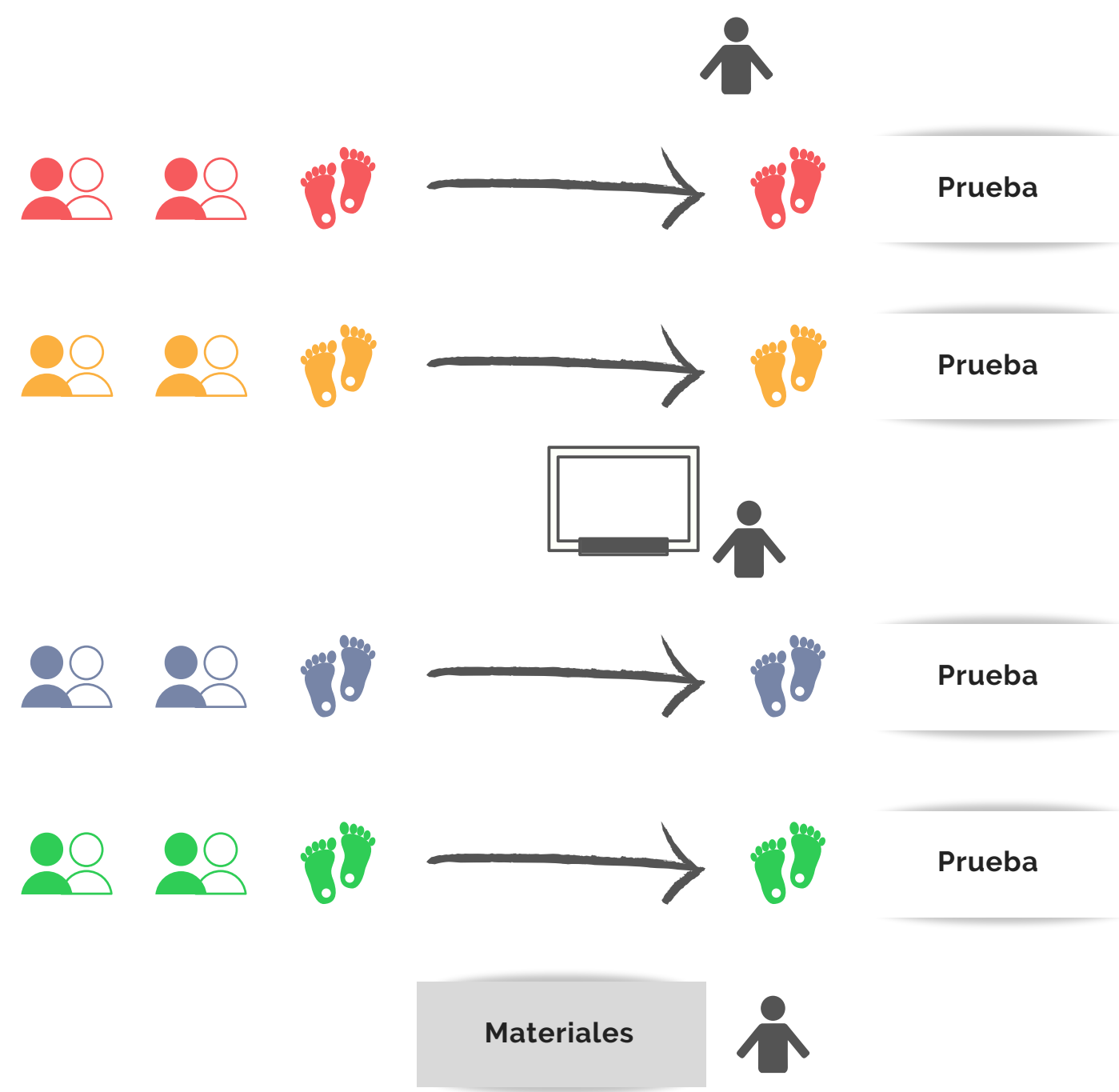

Figura 11. Organización y estructuración del espacio

Las explicaciones verbales de la sesión y de cada prueba se apoyaron con SPC (extraídos de ARASAAC) y demostraciones. Los pictogramas fueron mostrados de forma secuencial para no saturar de información a los participantes. Para ello, 
en la parte principal de la pista, había una pizarra. En el lado visible para los asistentes, únicamente se incluía la información de la prueba. En el otro lado, estaba el resto de la información. Los pictogramas se iban intercambiando al finalizar cada prueba para facilitar la comprensión de la tarea. A continuación, pueden observarse las explicaciones basadas en SPC para cada una de las pruebas (Tabla 2).

\subsection{Evaluación de la experiencia}

Durante la evaluación se tuvieron en cuenta tanto los aspectos positivos como aquellos susceptibles de mejora.

\section{Aspectos metodológicos a destacar}

Uno de los aspectos que más influyó en el desarrollo satisfactorio de la sesión fue la planificación previa. En este sentido, solicitamos información a Asociación Autismo Huesca para conocer las características y el grado de afectación de TEA de los asistentes. La información relativa a las capacidades, limitaciones, estereotipias, relación social y canal de comunicación nos permitió adaptar las pruebas y la transmisión de la información a las características y necesidades de los participantes con TEA. Del mismo modo, conocer sus características nos facilitó la organización de equipos mixtos y heterogéneos.

Por otro lado, el ambiente predecible y estructurado, a través de pruebas con un inicio y un final predeterminado, favoreció que los participantes comprendieran la tarea. Asimismo, la utilización de un reducido número de materiales en cada actividad evitó la sobre-estimulación al existir menos estímulos. Probablemente, los recursos utilizados para trabajar el turno y la espera (mediante figuras de pies en el suelo y un sistema de colores) y la ejecución en parejas contribuyeron en el buen funcionamiento de las pruebas.

Otro de los factores que pudo influir en la comprensión de la tarea fue el canal de recepción de información (verbal y visual) y la información breve, concisa y secuencial, acompañada siempre de demostraciones.

Tabla 2. Explicaciones basadas en SPC para cada una de las pruebas

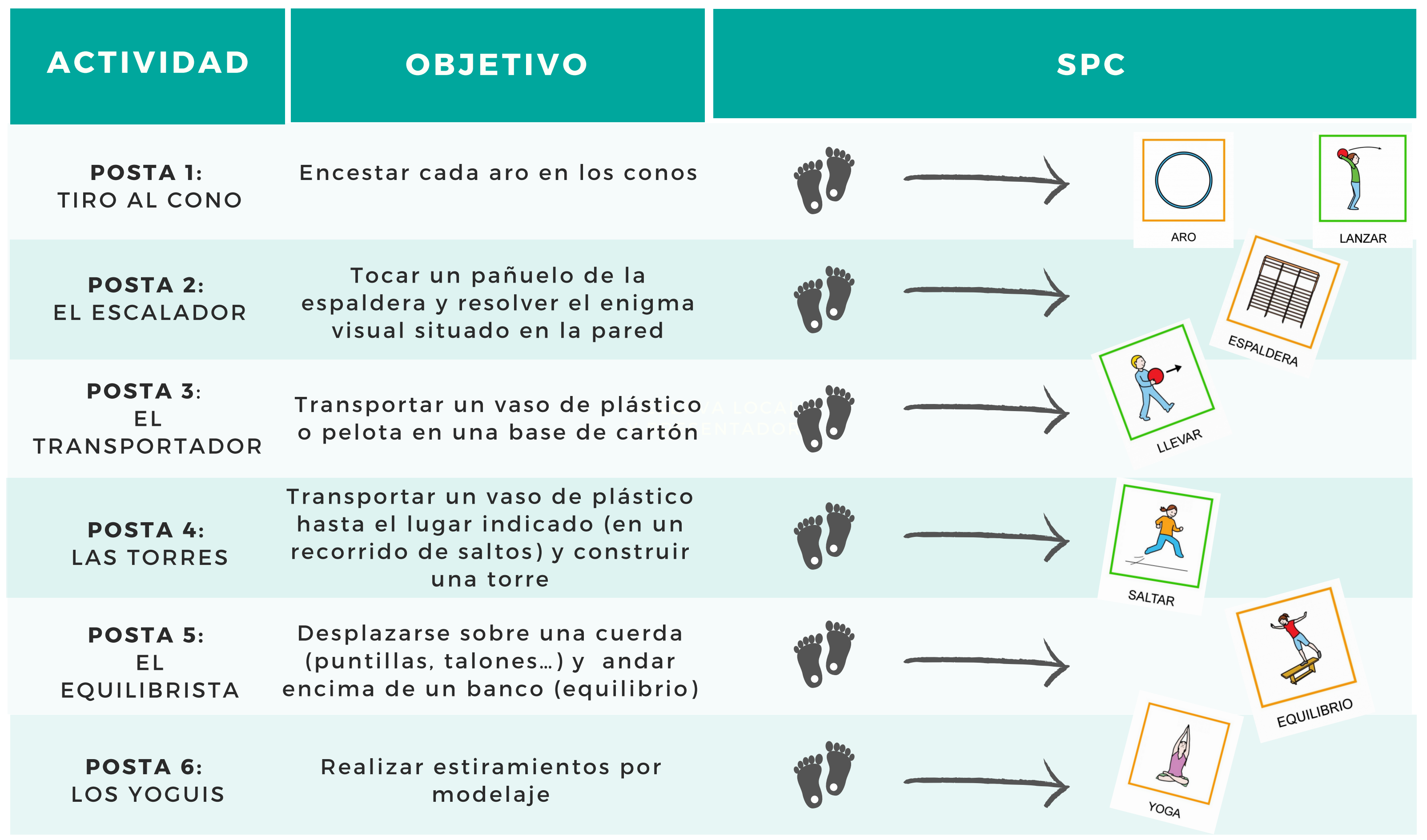

Nota: Además de los SPC, las explicaciones se acompañaron de demostraciones e informaciones verbales concisas

Autor de los pictogramas (pictograma aro, pictograma lanzar, pictograma espaldera, pictograma llevar, pictograma saltar, pictograma equilibrio, pictograma yoga): Sergio Palao. Procedencia: ARASAAC (http://arasaac.org) Licencia: CC (BY-NC-SA). 
Por último, cabe destacar que se usó un feedback privado (dirigido a cada pareja o equipo), positivo e interrogativo (por ejemplo, ¿cómo debemos colocar el vaso para construir una torre?) con objeto de favorecer tanto el aprendizaje como la motivación de los participantes en la ejecución de las pruebas. La cantidad de feedback no fue muy elevada para evitar la sobre-estimulación y el exceso de ayuda y dependencia.

\section{Aspectos susceptibles de mejora}

El hecho de que en la sesión hubiese personas con TEA y estudiantes neurotípicos hizo que la dificultad de las pruebas no fuese, en ocasiones, la misma para todos los asistentes. En este sentido, el descanso a mitad de la sesión no fue necesario para el alumnado neurotípico. Además, en futuras sesiones parece necesario incorporar más variantes que atiendan a todos los niveles de competencia motriz.

La diversidad en cuanto a condición física, canal de recepción de información, etc. conllevó a planificar con flexibilidad, adaptando cada actividad al grupo y a sus características (por ejemplo, al observar que el grupo respondía de forma satisfactoria a las demostraciones y ejemplificaciones, se decidió que la vuelta a la calma fuera por modelaje, lo cual no estaba previsto en la planificación inicial). Asimismo, los asistentes neurotípicos no percibieron el mismo grado de desafío ni de relación social. Esto pudo explicarse dada la presencia de algunas personas no-verbales ( $\sin$ comunicación verbal o habla), con las cuales la interacción social fue menor. A pesar de que las rotaciones pudieran haber favorecido el contacto entre todos los asistentes, no parece recomendable, en una primera sesión, cambiar los componentes de cada grupo y el espacio sistemático.

Aunque se ha comentado que el uso mínimo de material favoreció el orden, cabe destacar que el uso de una pelota provocó una sobre-estimulación en un participante. Por ello, resulta necesario conocer de antemano aquellos elementos que podrian desencadenar comportamientos desajustados o estereotipados. En esta situación fue necesario que los profesionales de Asociación Autismo Huesca supervisaran el comportamiento de esa persona, lo que puso de manifiesto la necesidad de tener personal de apoyo para los asistentes con TEA pronunciado.

Aunque la sesión tuvo algunos aspectos susceptibles de mejora, fue evaluada de forma positiva tanto por el alumnado neurotípico, como por las familias y los profesionales de Asociación Autismo Huesca. En el primero de los casos respondieron a un cuestionario de opción múltiple (cuyas respuestas oscilaban entre 1 y 5, siendo esta última la de mayor puntuación) donde se evaluó el grado de diversión, la idoneidad de la sesión para el colectivo al que nos dirigíamos y para el trabajo de las habilidades motrices básicas, la comunicación y la relación social. Todos los ítems fueron valorados con puntuaciones entre 4 y 5 , a excepción de la variable de relación social, presentando una puntuación media de 3,6. Este factor pudo deberse a que los integrantes de los equipos no se intercambiaron con otros grupos, permaneciendo estables a lo largo de toda la sesión. Sin embargo, se consideró acertado preservar los mismos equipos para minimizar los cambios de espacio. Además, este aspecto también pudo favorecer la afiliación entre los miembros de cada grupo, mejorando la cohesión grupal entre ellos al permanecer más tiempo juntos.

Asimismo, las familias y el equipo de Asociación Autismo Huesca realizaron una evaluación muy positiva a través de preguntas abiertas:

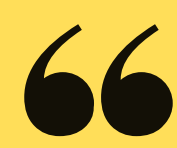

"Me dijo que se lo ex plicaron súper bien, que es la primera vez que lo había entendido todo. Estaba contentísima, me dijo si lo harían más veces, así que muchas gracias" (Familiar de una participante con TEA socia de Asociación Autismo Huesca).

"Fue una experiencia para grabar y revisar, porque si hay una manera de aplicar las pautas que pueden facilitar que las personas con TEA se lleven la sensación de que han hecho algo funcional y relevante, que les ha supuesto una ganancia, la conseguisteis el martes" (Supervisores Asociación Autismo Huesca). 


\section{Conclusiones}

Dada la actual prevalencia del TEA, puede ser habitual que tengamos en el contexto educativo y deportivo personas con rasgos de este trastorno. Sin embargo, diversas investigaciones han mostrado que los educadores físicos carecen de las herramientas $\mathrm{y} / \mathrm{o}$ conocimientos necesarios para atender las necesidades específicas que presentan estas personas. Por ello, comprender las características que se asocian con el TEA podría ayudar al desarrollo de estrategias metodológicas específicas en el contexto físico-deportivo.

La AF se ha mostrado eficaz para reducir las dificultades que presentan las personas con TEA en las áreas de comunicación, relación social y comportamientos restringidos o repetitivos. Sin embargo, las personas con TEA perciben numerosas barreras para la práctica de AF, especialmente barreras individuales (por ejemplo, menor relación social), familiares (como la falta de apoyo) y comunitarias (falta de oportunidades). Por ello, es importante diseñar estrategias que permitan superar estas barreras para que esta población adopte un estilo de vida más activo.

En base a la literatura científica, en esta guía se han identificado diez estrategias que podrian ser efectivas para el diseño e implementación de activi- dades físico-deportivas (Figura 12). Sin embargo, dada la diversidad de este trastorno, no existe una estrategia metodológica única, siendo necesario adaptar dichas orientaciones a cada caso individual.

La participación de las personas con TEA en las actividades físico-deportivas puede ser satisfactoria si se llevan a cabo las modificaciones y adaptaciones pertinentes que faciliten su integración. Además, existen algunas metodologías de trabajo como el método TEACCH que fomenta la independencia del alumnado, al trabajar la estructuración del entorno mediante apoyos visuales, haciendo el espacio más comprensible.

Por otro lado, los profesionales de la educación, el ocio y el deporte deben conocer las características de cada persona y familiarizarse con los recursos, rutinas y elementos que se asocian con el TEA. Para ello, puede ser recomendable trabajar junto a los profesionales de referencia y las familias.

Por último, este trabajo ofrece una experiencia práctica con Asociación Autismo Huesca donde se implementan algunas de las estrategias expuestas en un grupo de personas con TEA y estudiantes neurotípicos

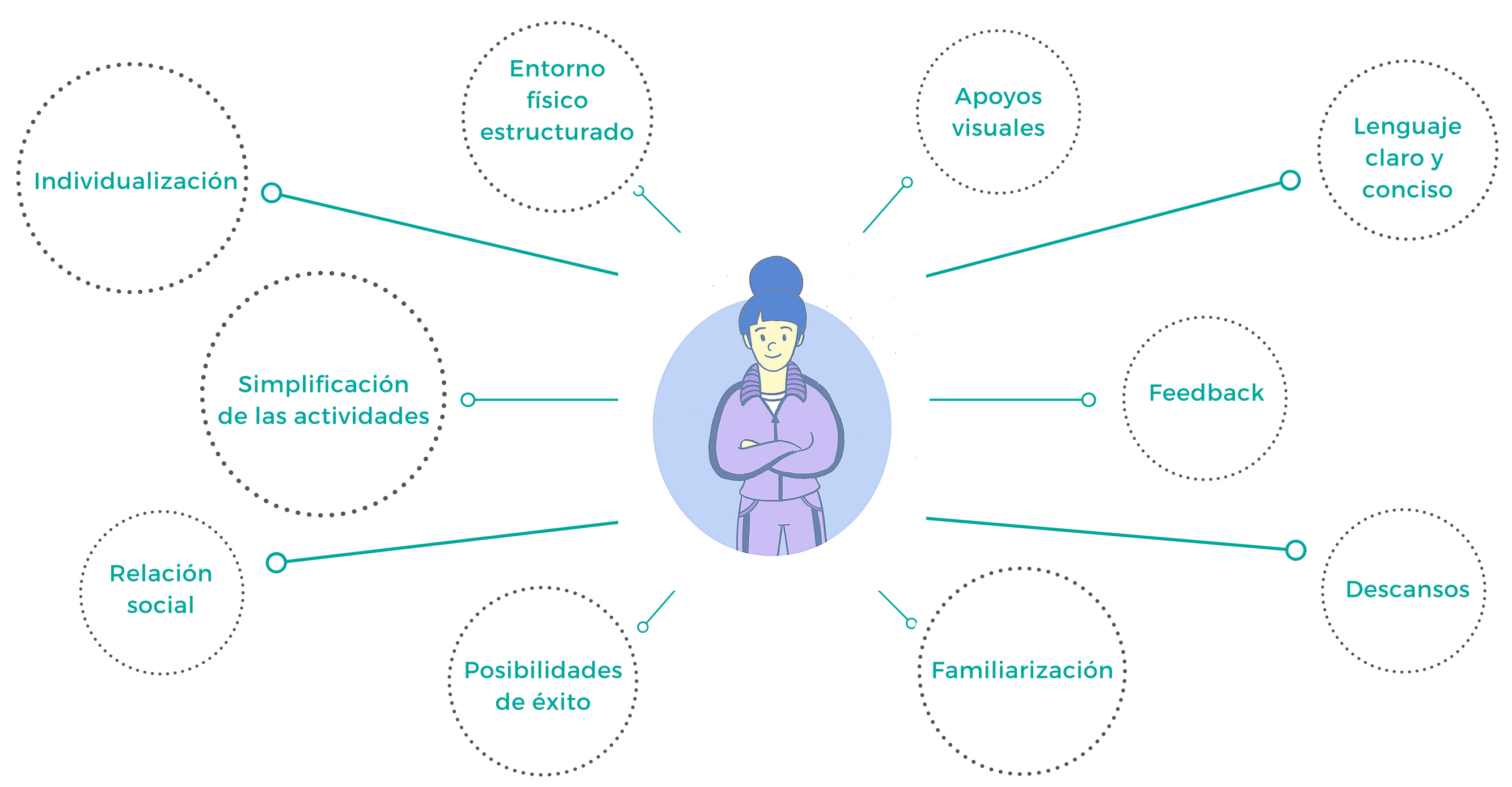

Figura 12. Estrategias efectivas para el diseño e implementación de actividades fisico-deportivas para personas con TEA 


\section{Otras propuestas y recursos de interés en personas con Trastorno del Espectro del Autismo}

\section{Videoteca:}

- El viaje de Maria:

Amaya Ariz Argaya. (07 de septiembre de 2014). El viaje de María. [Archivo de video]. Youtube. Recuperado de: https://www.youtube.com/watch? $v=t x d j o 2 T d V 4 k \& t=9 s$

\section{- Academia de especialistas:}

Orange España. (13 de septiembre de 2012). Academia de especialistas. [Archivo de video]. Youtube. Recuperado de: https://www.youtube.com/watch?V=LVao2G_DR_8

\section{- Mi Hermanito de la Luna:}

Emilytahh. (16 de julio de 2009). Mi Hermanito de la Luna. [Archivo de video]. Recuperado de: https://www.youtube.com/watch?V=OHRD310kVOY

- Cómo percibe el mundo una persona con autismo:

Débora Esther Feinmann. (21 de agosto de 2013). Cómo percibe el mundo una persona con autismo. [Archivo video]. Recuperado de:

https://wWw.youtube.com/watch?v=Nskmiv_MNHI

\section{- Por 4 esquinitas de nada:}

MayteCalavia. (01 de abril de 2011). Por 4 esquinitas de nada. [Archivo video]. Recuperado de: https://www.youtube.com/watch?v=DBjka_zQBdQ

\section{- Hugo, un amigo con Asperger:}

Instituto AGL. (20 de septiembre de 2012). Hugo, un amigo con Asperger. [Archivo video]. Recuperado de: https://www.youtube.com/watch?v=mzl33DR2rnM

\section{- Tea Informe Robinson Autismo, Competir con Uno Mismo:}

El rincón del buho claro tea y tut. (18 de septiembre de 2017). TEA Informe Robinson Autismo, Competir con uno mismo. Recuperado de: https://www.youtube.com/watch?v=Ky4NRG_Hatg

\section{Páginas relevantes:}

\section{- Confederación Autismo España.}

Recuperado de: http://Www.autismo.org.es/sobrelos-TEA

\section{- Aetapi. Profesionales del Autismo:}

Recuperado de: http://aetapi.org/

\section{- Doctor TEA:}

Recuperado de: http://Www.doctortea.org/

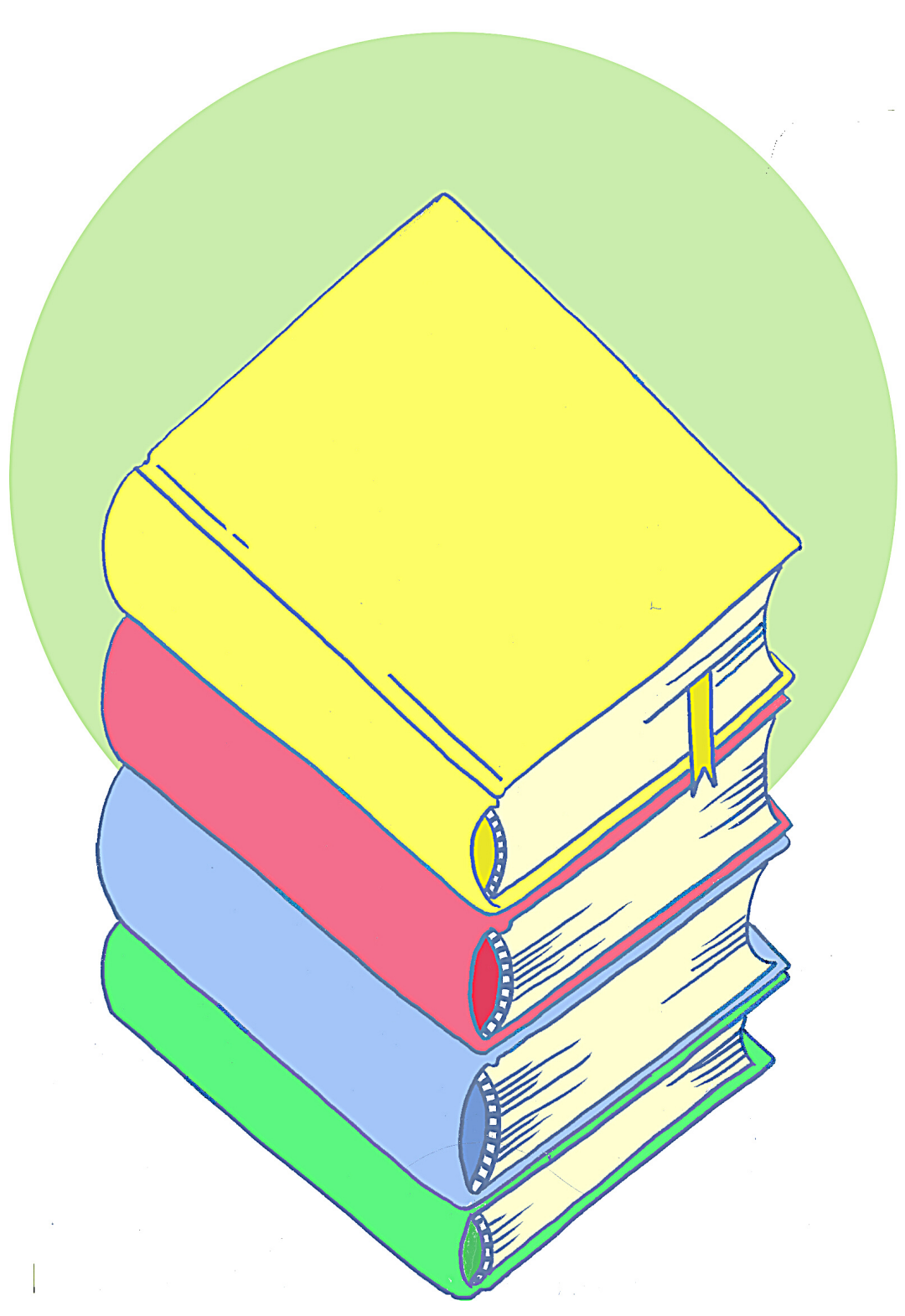




\section{- Autismo Diario:}

Recuperado de: https://autismodiario.org

\section{- Autismo Madrid:}

Recuperado de: http://autismomadrid.es

\section{- Aprendices visuales. Escuelas visuales:}

Recuperado de:

https://aprendicesvisuales.com/p/escuelasvisuales

- Accesibilidad y capacidades cognitivas. Orientación en todos los espacios para todas las personas:

Recuperado de:

http://accesibilidadcognitivaurbana.fundaciononce. es/origenProyecto.aspx

\section{- Ocupatea:}

Recuperado de: http://ocupatea.es/

Gobierno de Aragón:

\section{- Gobierno de Aragón. ARASAAC:}

Recuperado de: http://www.arasaac.org/

- Inclusión y Autismo. Equipo especializado de orientación educativa en TEA:

Recuperado de:

http://orientacionautismo.catedu.es/

- Fundación Orange. "TEAyudo a jugar":

Recuperado de:

http://www.fundacionorange.es/aplicaciones/teayu do-a-jugar/

\section{- Habla signada:}

Recuperado de:

https://hablasignada.divertic.org/buscar.php

\section{- Les pictogrammes:}

Recuperado de:

https://www.lespictogrammes.com/

- Plena inclusión:

Recuperado de: https://WWW.plenainclusion.org/

- Hop Toys:

Recuperado de:

https://www.hoptoys.es/autonomia-c-868.html

\section{- Conexión Autismo:}

Recuperado de: http://conexionautismo.com/quees-el-autismo/conecta-con-el-autismo/

\section{- Asociación Proyecto Autismo (ASPAU):}

Recuperado de: http://www.aspau.org/

\section{- Autismo Burgos:}

Recuperado de: http://WWw.autismoburgos.es/

\section{- Autismo Ávila:}

Recuperado de: http://www.autismoavila.org

\section{- Asociación Autismo Huesca:}

Recuperado de: https://www.autismohuesca.es/

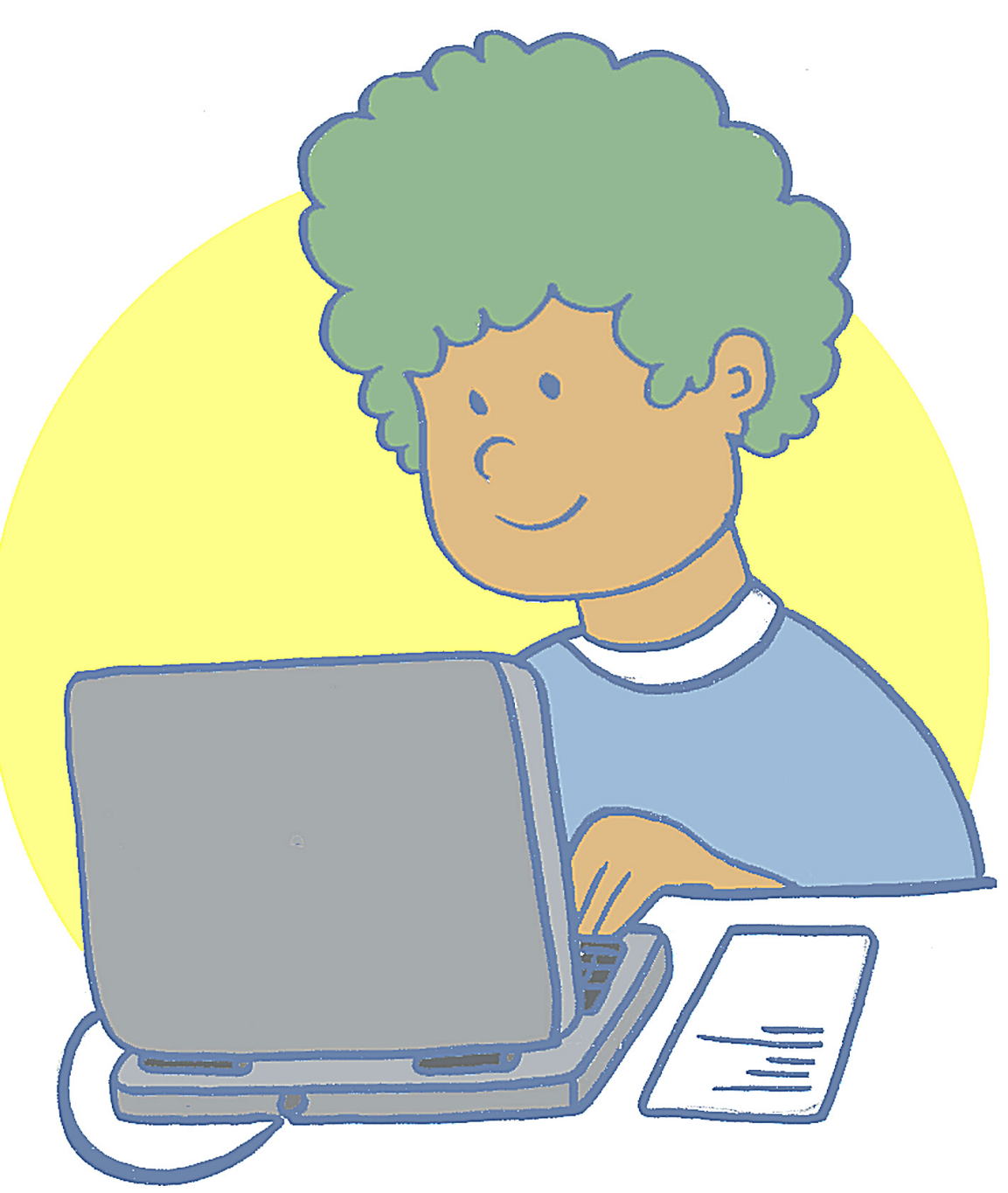




\section{Referencias bibliográficas}

Abarca, A. (2015). Secuenciación de juegos populares en educación física con alumnado diagnosticado dentro del Trastorno del Espectro Autista. Tándem. Didáctica de la Educación Física, 47, 65-73.

American Psychiatric Association. (2014). Guía de consulta de los criterios diagnósticos del DSM-5®: Spanish Edition of the Desk Reference to the Diagnostic Criteria From DSM-5®. American Psychiatric Pub.

Aniszewski, E., Almeida, H., y Alvernaz, A. (2020). Benefits of physical activity for the development of autistic children. International Physical Medicine \& Rehabilitation Journal, 5(2), 79-80. https://doi.org/10.15406/ipmrj.2020.05.00233

Arasaac. Portal aragonés de la Comunicación Alternativa y Aumentativa. Herramientas online. Recuperado de: http://www.arasaac.org/herramientas.php

Arasaac. Portal aragonés de la Comunicación Alternativa y Aumentativa. ¿Qué son los sistemas aumentativos y alternativos de comunicación (SAAC)? Recuperado de: http://www.arasaac.org/aac.php

Asociación Navarra de Autismo. Metodología de aprendizaje Teacch. Recuperado de: http://www.autismonavarra.com/2016/08/metodologia-de-aprendizaje-teacch/

Asún, S. (2016). Actividad física y deporte adaptado a personas con discapacidad. Zaragoza, España: $1^{\circ}$ ed. Universidad de Zaragoza.

Autismo Diario (2011). El método TEACCH. Recuperado de: https://autismodiario.com/wpcontent/uploads/2011/03/resumenTEACCH.pdf

Autismo Diario. (2018). Los Sistemas Alternativos y Aumentativos de Comunicación (SAAC) y el desarrollo del lenguaje. Recuperado de: https://autismodiario.com/2018/03/10/sistemas-alternativos-y-aumentativos-decomunicacion-saac/

Autismo Madrid (2013). Las Estereotipias en las personas con TEA: Consejos para trabajarlas. Recuperado de: https://autismomadrid.es/libros-federacion-autismo-madrid-blog/las-estereotipias-en-las-personas-con-tea/

Baio, J., Wiggins, L., Christensen, D. L., Maenner, M. J., Daniels, J., Wa-rren, Z.,... Durkin, M. S. (2018). Prevalence of autism spectrum disorder among children aged 8 years autism and developmental disabilities moni-toring network, 11 sites, United States, 2014. MMWR Surveillance Summries, 67(6), 1-23. Recuperado de: https://www.ncbi.nlm.nih.gov/pmc/articles/PMC5919599/pdf/ss6706a1.pdf

Barrios,J. L., Blau, A., y Forment, C. (2018). Trastorno del Espectro del Autismo. Una guía para la comunidad Educativa. Generalitat Valenciana. Recuperado de: http://www.ceice.gva.es/es/web/inclusioeducativa/publicacionsdgie

Beamer, J. A., y Yun, J. (2014). Physical educators' beliefs and self-reported behaviors toward including students with autism spectrum disorder. Adapted Physical Activity Quarterly, 31(4), 362-376. https://doi.org/10.1123/apaq.2014-0134 
Bhat, A. N., Landa, R. J., y Galloway, J. C. (2011). Current perspectives on motor functioning in infants, children, and adults with autism spectrum disorders. Physical Therapy, 91(7), 1116-1129. https://doi.org/10.2522/ptj.20100294

Brown, D. M., Arbour-Nicitopoulos, K. P., Martin, K. A., Latimer-Cheung, A. E., y Bassett-Gunter, R. L. (2020). Examining the relationship between parent physical activity support behaviour and physical activity among children and youth with autism spectrum disorder. Autism. https://doi.org/10.1177/1362361320922658

Chaput, J. P., Carson, V., Gray, C. E., y Tremblay, M. S. (2014). Importance of all movement behaviors in a 24 hour period for overall health. International Journal of Environmental Research and Public Health, 11(12), 12575-12581. https://doi.org/10.3390/ijerph111212575

Colombo-Dougovito, A. M., y Block, M. E. (2019). Fundamental motor skill interventions for children and adolescents on the autism spectrum: A literature review. Review Journal of Autism and Developmental Disorders, 1-13. https://doi.org/10.1007/s40489-019-00161-2.

Colombo-Dougovito, A. M., Blagrave, A. J., y Healy, S. (2020). A grounded theory of adoption and maintenance of physical activity among autistic adults. Autism. https://doi.org/10.1177/1362361320932444

Confederación Autismo España. Sobre el Tea. Recuperado de: http://www.autismo.org.es/sobre-los-TEA

Cudolá, J. E. (2016). Sistemas alternativos y aumentativos de comunicación para el tratamiento de niños con trastorno del espectro autista. Diálogos Pedagógicos, 14(28), 104-126.

Cuesta, J. L., de la Fuente, R., Vidriales, R., Hernández, C., Sanz, M. P., y González, J. (2017). Bienestar físico, dimensión clave de la calidad de vida en las personas con autismo. Revista INFAD de Psicología. International Journal of Developmental and Educational Psychology, 4(1), 33-44. https://doi.org/10.17060/ijodaep.2017.n1.v4.1025

Dempsey, P. C., Matthews, C. E., Dashti, S. G., Doherty, A. R., Bergouignan, A., van Roekel, E. H., ... Lynch, B. M. (2020). Sedentary behavior and chronic disease: mechanisms and future directions. Journal of Physical Activity and Health, 17(1), 52-61. https://doi.org/10.1123/jpah.2019-0377

Downey, R., y Rapport, M. J. K. (2012). Motor activity in children with autism: a review of current literature. Pediatric Physical Therapy, 24(1), 2-20. https://doi.org/10.1097/PEP.0b013e31823db95f

Duquette, M. M., Carbonneau, H., Roult, R., y Crevier, L. (2016). Sport and physical activity: facilitating interventions with young people living with an autism spectrum disorder. Physical Activity Review, 4, 40-49. http://doi.org/10.16926/par.2016.04.05

Fedewa, A. L., y Ahn, S. (2011). The effects of physical activity and physical fitness on children's achievement and cognitive outcomes: a meta-analysis. Research Quarterly for Exercise and Sport, 82(3), 521-535. https://doi.org/10.1080/02701367.2011.10599785

Fernández, J. J. (2011). La actividad físico-deportiva como base para la integración en el área de educación física: autistas. EmásF: Revista Digital de Educación Física, 8, 24-31.

Fittipaldi-Wert, J., y Mowling, C. M. (2009). Using visual supports for stu-dents with autism in physical education. Journal of Physical Education, Recreation \& Dance, 80(2), 39-43. http://doi.org/10.1080/07303084.2009.10598281 
Gómez, M., Valero, A., Peñalber, I., y Velasco, M. (2008). El trabajo de la motricidad en la clase de Educación Física con niños autistas a través de la adaptación del lenguaje Benson Schaeffer. Revista Iberoamericana de Educación, 46, 175-92.

Green, A., y Sandt, D. (2013). Understanding the picture exchange communication system and its application in physical education. Journal of Physical Education, Recreation \& Dance, 84(2), 33-39. https://doi.org/10.1080/07303084.2013.757190

Grenier, M., y Yeaton, P. (2011). Previewing: A successful strategy for students with autism. Journal of Physical Education, Recreation \& Dance, 82(1), 28-43. https://doi.org/10.1080/07303084.2011.10598558

Healy, S., Patterson, F., Williams, E., Lozano, A. J., Hanlon, A. L., y Obrusnikova. I. (2020). Rethinking daily movement behaviours of children with autism spectrum disorder: meeting the 24-hour movement guidelines. European Journal of Adapted Physical Activity, 13(8). http://doi.org/10.5507/euj.2020.006

Heredia, J., y Duran, D. (2017). Aprendizaje cooperativo en educación física para la inclusión de alumnado con rasgos autistas. Revista de Educación Inclusiva, 6(3), 25-40.

Hillier, A., Buckingham, A., y Schena, D. (2020). Physical activity among adults with autism: participation, attitudes, and barriers. Perceptual and Motor Skills. http://doi.org/10.1177/0031512520927560

Hodges, H., Fealko, C., y Soares, N. (2020). Autism spectrum disorder: definition, epidemiology, causes, and clinical evaluation. Translational Pediatrics, 9(1), 55-65. http://doi.org/10.21037/tp.2019.09.09

Howells, K., Sivaratnam, C., May, T., Lindor, E., McGillivray, J., y Rinehart, N. (2019). Efficacy of group-based organised physical activity participation for social outcomes in children with autism spectrum disorder: a systematic review and meta-analysis. Journal of Autism and Developmental Disorders, 49(8), 3290-3308. http://doi.org/10.1007/s10803-019-04050-9.

Huang, J., Du, C., Liu, J., y Tan, G. (2020). Meta-analysis on intervention effects of physical activities on children and adolescents with autism. International Journal of Environmental Research and Public Health, 17(6), 1950. http://doi.org/10.3390/ijerph17061950

Jones, R. A., Downing, K., Rinehart, N. J., Barnett, L. M., May, T., McGillivray, J. A., ... Hinkley, T. (2017). Physical activity, sedentary behavior and their correlates in children with Autism Spectrum Disorder: A systematic review. Plos One 12(2), e0172482. http://doi.org/10.1371/journal.pone.0172482

LaLonde, K. B., MacNeill, B. R., Eversole, L. W., Ragotzy, S. P., y Poling, A. (2014). Increasing physical activity in young adults with autism spectrum disorders. Research in Autism Spectrum Disorders, 8(12), $1679-1684$. https://doi.org/10.1016/j.rasd.2014.09.001

Lang, R., Koegel, L. K., Ashbaugh, K., Regester, A., Ence, W., y Smith, W. (2010). Physical exercise and individuals with autism spectrum disorders: A systematic review. Research in Autism Spectrum Disorders, 4(4), 565-576. https://doi.org/10.1016/j.rasd.2010.01.006

LeBlanc, A. G., Boyer, C., Borghese, M. M., Chaput, J. P., Leduc, G., Tremblay, M. S., y Longmuir, P. E. (2016). Canadian Physical Activity and Screen Time Guidelines: Do Children Know?. Health Behavior and Policy Review, 3(5), 444-454. https://doi.org/10.14485/HBPR.3.5.5 
Liang, X., Li, R., Wong, S. H., Sum, R. K., y Sit, C. H. (2020). Accelerometer-measured physical activity levels in children and adolescents with autism spectrum disorder: A systematic review. Preventive Medicine Reports, 19. https://doi.org/10.1016/j.pmedr.2020.101147

Lobenius-Palmér, K., Sjöqvist, B., Hurtig-Wennlöf, A., y Lundqvist, L. O. (2018). Accelerometer-assessed physical activity and sedentary time in youth with disabilities. Adapted Physical Activity Quarterly, 35(1), 1-19. https://doi.org/10.1123/apaq.2015-0065

Locke, J., Ishijima, E. H., Kasari, C., y London, N. (2010). Loneliness, friendship quality and the social networks of adolescents with high-functioning autism in an inclusive school setting. Journal of Research in Special Educational Needs, 10(2), 74-81. https://doi.org/10.1111/j.1471-3802.2010.01148.x

Maher, A. J. (2017). 'We've got a few who don't go to PE' Learning support assistant and special educational needs coordinator views on inclusion in physical education in England. European Physical Education Review, 23(2), 257-270. https://doi.org/10.1177/1356336X16649938

Martin, C. S. (2016). Exploring the impact of the design of the physical classroom environment on young children with autism spectrum disorder (ASD). Journal of Research in Special Educational Needs, 16(4), $280-298$. https://doi.org/10.1111/1471-3802.12092

McCoy, S. M., y Morgan, K. (2020). Obesity, physical activity, and sedentary behaviors in adolescents with autism spectrum disorder compared with typically developing peers. Autism, 24(2), 387-399. https://doi.org/10.1177/1362361319861579

Menear, K. S., y Neumeier, W. H. (2015). Promoting physical activity for students with autism spectrum disorder: barriers, benefits, and strategies for success. Journal of Physical Education, Recreation and Dance, 86(3), 43-48. https://doi.org/10.1080/07303084.2014.998395

Menear, K. S., y Smith, S. C. (2011). Teaching physical education to students with autism spectrum disorders. Strategies, 24(3), 21-24. https://doi.org/10.1080/08924562.2011.10590929

Nakutin, S. N., y Gutierrez, G. (2019). Effect of physical activity on academic engagement and executive functioning in children with asd. School Psychology Review, 48(2), 177-184. https://doi.org/10.17105/SPR-2017-0124.V48-2

Nichols, C., Block, M. E., Bishop, J. C., y Mclntire, B. (2019). Physical activity in young adults with autism spectrum disorder: Parental perceptions of barriers and facilitators. Autism, 23(6), $1398-1407$. https://doi.org/10.1177/1362361318810221

Organización Mundial de la Salud (2010). Recomendaciones mundiales sobre actividad física para la salud. Recuperado de https://apps.who.int/iris/bitstream/handle/10665/44441/9789243599977_spa.pdf

Organización Mundial de la Salud (2020). WHO Guidelines on physical activity and sedentary behaviour for children and adolescents, adults and older adults. Recuperado de: https://www.who.int/docs/default-source/physical-activity/callfor-consultation/draft-guideline-on-physical-activity-and-sedentray-behaviour.pdf?sfvrsn=ddf523d5_4

Patterson, R., McNamara, E., Tainio, M., de Sá, T. H., Smith, A. D., Sharp, S. J., ... Wijndaele, K. (2018). Sedentary behaviour and risk of all-cause, cardiovascular and cancer mortality, and incident type 2 diabetes: a systematic review and dose response meta-analysis. European Journal of Epidemiology, 33, 811-829. https://doi.org/10.1007/s10654018-0380-1 
Real Decreto Legislativo 1/2013, de 29 de noviembre, por el que se aprueba el Texto Refundido de la Ley General de derechos de las personas con discapacidad y de su inclusión social. Recuperado de: https://www.boe.es/buscar/doc.php?id=BOE-A-2013-12632

Reid, G., O'Connor, J., y Lloyd, M. (2003). The autism spectrum disorders. physical activity instruction. Part III. Palestra, 19(2), 20-26.

Reinders, N. J., Branco, A., Wright, K., Fletcher, P. C., y Bryden, P. J. (2019). Scoping review: physical activity and social functioning in young people with autism spectrum disorder. Frontiers in Psychology, $10,120$. https://doi.org/10.3389/fpsyg.2019.00120

Rivière, A. (2001). Autismo: enfoques actuales para padres y profesionales de la salud y la educación. Tomo I. Fundec.

Rivière, A. (2001). Autismo: enfoques actuales para padres y profesionales de la salud y la educación. Tomo II. Fundec.

Ruggeri, A., Dancel, A., Johnson, R., y Sargent, B. (2019). The effect of motor and physical activity intervention on motor outcomes of children with autism spectrum disorder: A systematic review. Autism, 24(3), 544-568. https://doi.org/10.1177/1362361319885215

Ruíz, D. B., Pastor, T. G., Salinero, J. J., Theirs, C. I., Nombre, D., Guitián, C., ... Soriano, M. L. (2015). Descripción de la práctica de actividad física, habilidades motrices básicas y composición corporal en niños y jóvenes de espectro autista. Diferencias por sexo. Retos: Nuevas Tendencias en Educación Física, Deporte y Recreación, 28, 61-65.

Sánchez-Blanchart, J., Sánchez-Oliva, A., Pastor-Vicedo, J. C., y Martínez-Martínez, J. (2019). La formación docente ante el trastorno del espectro autista. SPORT TK-Revista EuroAmericana de Ciencias del Deporte, 8(2), 59-66.

Sanz-Cervera, P., Fernández-Andrés, M. I., Pastor-Cerezuela, G., y Tárraga-Mínguez, R. (2018). Efectividad de las intervenciones basadas en metodología TEACCH en el trastorno del espectro autista: un estudio de revisión. Papeles del Psicólogo, 39(1), 40-50.

Scharoun, S. M., Wright, K. T., Robertson-Wilson, J. E., Fletcher, P. C., y Bryden, P. J. (2017). Physical activity in individuals with autism spectrum disorders (ASD): a review. En M. Fitzgerald y J. Yip (Eds.). Paradigms, Recent Research and Clinical Applications (pp. 301-331). IntechOpen, Croacia. https://doi.org/10.5772/66680

Sherman, R. (2019). The Effects of Physical Activity on Inappropriate Behaviors of School-Aged Students with Autism Spectrum Disorders. Recuperado de: https://digitalcommons.brockport.edu/cgi/viewcontent.cgi? article $=1092 \&$ context $=$ pes_synthesis

Simón-Montañés, L., Pastor, D., y Viñas, D. (2019). Trastorno del Espectro Autista (TEA) y promoción de la actividad física: una experiencia inclusiva a través del desarrollo de habilidades motrices básicas. Congreso Internacional Capas-Ciudad. Liderazgo en la promoción de actividad física: Estrategias efectivas en la movilización de activos.ISBN: 978-84-18321-04-7

Simpson, C. G., Gaus, M. D., Biggs, M. J. G., y Williams Jr, J. (2010). Physical education and implications for students with Asperger's syndrome. Teaching Exceptional Children, 42(6), 48-56. https://doi.org/10.1177/004005991004200606 
Sorensen, C., y Zarrett, N. (2014). Benefits of physical activity for adolescents with autism spectrum disorders: A comprehensive review. Review Journal of Autism and Developmental Disorders, 1(4), $344-353$. https://doi.org/10.1007/s40489-014-0027-4

Srinivasan, S. M., Pescatello, L. S., y Bhat, A. N. (2014). Current perspectives on physical activity and exercise recommendations for children and adolescents with autism spectrum disorders. Physical Therapy, 94(6), 875-889.

Staples, K., Todd, T., y Reid, G. (2006). Physical activity instruction and autism spectrum disorders. ACHPER Healthy Lifestyles Journal, 53(3-4), 17-23.

Stins, J. F., y Emck, C. (2018). Balance performance in autism: A brief overview. Frontiers in Psychology, 9 , 901. https://doi.org/10.3389/fpsyg.2018.00901

Suárez-Manzano, S., López-Serrano, S., de Oliveira, P. B., y da Cruz Murta, L. M. (2019). El ejercicio físico en el aula para la mejora del comportamiento de niños autistas. Revista Iberoamericana de Ciencias de la Actividad Física y el Deporte, 8(1), 136-148. https://doi.org/10.24310/riccafd.2019.v8i1.5792

Tan, B. W., Pooley, J. A., y Speelman, C. P. (2016). A meta-analytic review of the efficacy of physical exercise interventions on cognition in individuals with autism spectrum disorder and ADHD. Journal of Autism and Developmental Disorders, 46(9), 3126-3143. https://doi.org/10.1007/s10803-016-2854-x

Tremblay, M. S., Carson, V., Chaput, J. P., Connor Gorber, S., Dinh, T., Duggan, M., ... Janssen, I. (2016). Canadian 24-hour movement guidelines for children and youth: an integration of physical activity, sedentary behaviour, and sleep. Applied Physiology, Nutrition, and Metabolism, 41(6), 311-327. https://doi.org/10.1139/apnm-2016-0151

Varin, B. (2019). The barriers to physical activity for individuals with autism spectrum disorders and strategies for overcoming these barriers. Kinesiology, Sport Studies, and Physical Education Synthesis Projects. 84. Recuperado de: https://digitalcommons.brockport.edu/pes_synthesis/84

Weihrauch-Blüher, S., Schwarz, P., y Klusmann, J. H. (2018). Childhood obesity: increased risk for cardiometabolic disease and cancer in adulthood. Metabolism, 92, 147-152. https://doi.org/10.1016/j.metabol.2018.12.001

Wing, L., y Potter, D. (1999). Apuntes sobre la prevalencia del espectro autista. En Congreso en Internet autism99. Recuperado en: http://espectroautista.info/prevalencia.html 
$44 \mid$ 



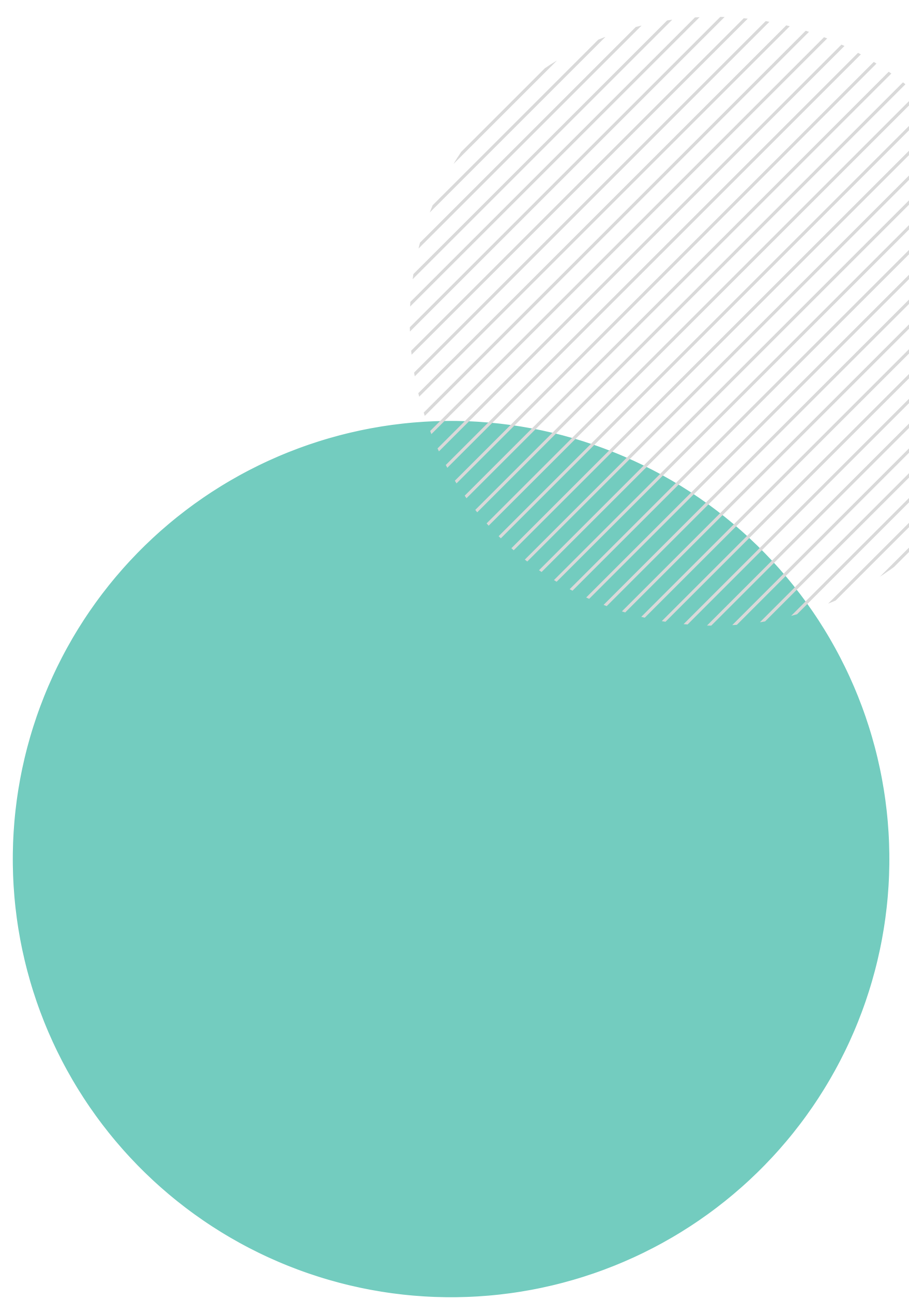

nenenen

A Servicio de

드 Publicaciones

1542 UniversidadZaragoza 